\title{
A balanced calibration of water quantity and quality by multi-objective optimization for integrated water system model
}

\author{
Yongyong Zhang a,*, Quanxi Shao ${ }^{\mathrm{b}, *}$, John A. Taylor ${ }^{\mathrm{c}}$ \\ ${ }^{a}$ Key Laboratory of Water Cycle and Related Land Surface Processes, Institute of Geographic Sciences and Natural Resources Research, Chinese Academy of Sciences, \\ Beijing 100101, China \\ ${ }^{\mathrm{b}}$ CSIRO Digital Productivity Flagship, Leeuwin Centre, 65 Brockway Road, Floreat Park, WA 6014, Australia \\ ${ }^{\text {c } C S I R O ~ D i g i t a l ~ P r o d u c t i v i t y ~ F l a g s h i p, ~ G P O ~ B o x ~ 664, ~ C a n b e r r a, ~ A C T ~ 2601, ~ A u s t r a l i a ~}$
}

\section{A R T I C L E I N F O}

\section{Article history:}

Received 16 April 2015

Received in revised form 31 March 2016

Accepted 1 May 2016

Available online 7 May 2016

This manuscript was handled by

Konstantine P. Georgakakos, Editor-in-Chief,

with the assistance of Michael Bruen,

Associate Editor

\section{Keywords:}

Water quantity and quality

Multi-process calibration

Pareto optima front

Integrated water system model

\begin{abstract}
S U M M A R Y
Due to the high interactions among multiple processes in integrated water system models, it is extremely difficult, if not impossible, to achieve reasonable solutions for all objectives by using the traditional stepby-step calibration. In many cases, water quantity and quality are equally important but their objectives in model calibration usually conflict with each other, so it is not a good practice to calibrate one after another. In this study, a combined auto-calibration multi-process approach was proposed for the integrated water system model (HEQM) using a multi-objective evolutionary algorithm. This ensures that the model performance among inseparable or interactive processes could be balanced by users based on the Pareto front. The Huai River Basin, a highly regulated and heavily polluted region of China, was selected as a case study. The hydrological and water quality parameters of HEQM were calibrated simultaneously based on the observed series of runoff and ammonia-nitrogen $\left(\mathrm{NH}_{4}-\mathrm{N}\right)$ concentrations. The results were compared with those of the step-by-step calibration to demonstrate the rationality and feasibility of the multi-objective approach. The results showed that a Pareto optimal front was formed and could be divided into three clear sections based on the elastic coefficient of model performance between $\mathrm{NH}_{4}-\mathrm{N}$ and runoff, i.e., the dominated section for $\mathrm{NH}_{4}-\mathrm{N}$ improvement, the trade-off section between $\mathrm{NH}_{4}-\mathrm{N}$ and runoff, and the dominated section for runoff improvement. The trade-off of model performance between runoff and $\mathrm{NH}_{4}-\mathrm{N}$ concentration was clear. The results of the step-by-step calibration fell in the dominated section for $\mathrm{NH}_{4}-\mathrm{N}$ improvement, where just the optimum of the runoff simulation was achieved with a large potential to improve $\mathrm{NH}_{4}-\mathrm{N}$ simulation without a significant degradation of the runoff simulation. The overall optimal solutions for all the simulations appeared in the trade-off section. Therefore, the Pareto front provided different satisfactory solutions for users to choose according to their specific objectives. This study is expected to promote the application of multi-objective calibration in water system modeling, and provide scientific and technological supports for the implementation of integrated river basin management.
\end{abstract}

(c) 2016 Elsevier B.V. All rights reserved.

\section{Introduction}

Integrated water system modeling is a popular practice in water related sciences nowadays due to the availability of highperformance computing facilities, more data sources and intensive exchange of interdisciplinary knowledge (Kirchner, 2006). Such water system models can be divided into two major categories based on their original purposes. Hydrological models are formulated to simulate the dominant runoff process, as well as

\footnotetext{
* Corresponding authors. Tel.: +61 (8) 9333 6613; fax: +61 (8) 93336121.

E-mail addresses: Zhangyy003@igsnrr.ac.cn (Y.Y.Zhang), Quanxi.shao@csiro.au (Q.X. Shao).
}

its corresponding water quality and ecological processes (such as SWAT (Arnold et al., 1998), HSPF (Bicknell et al., 1993) and SHE (Refsgaard and Storm, 1995)), while biogeochemical models focus on pollutant transportation and transformation processes and vegetation physiological processes with water flows being just as one of the major constraints (such as EPIC (Sharpley and Williams, 1990), DNDC (Li et al., 1992; Deng et al., 2011) and APSIM (McCown et al., 1996)). Integrated water system models play a significant role in many aspects of river basin management such as flood forecasting, water resources allocation, pollution control, environmental flow assessment and climate change impact evaluation. 
However, parameter calibration is always one of the key issues in model applications, especially for the complicated integrated models mainly due to over-parameterization. Such issues restricted their usefulness and effectiveness to real resources management and decision making. Currently, manual trial-and-error or automatic calibration are the most pervasive approaches to obtain the estimates of parameter values (Boyle et al., 2000; Vrugt et al., 2003; Tang et al., 2006; Afshar and Hamideh, 2012; Huang, 2014). However, manual trial-and-error is a crude and inefficient method because it always depends on subjective justification of the optimal estimates (Afshar and Hamideh, 2012; Huang, 2014). Along with the increasing computing efficiency, the automatic calibration approach has become more popular, together with the development of optimization algorithms.

In practice, the commonly used calibration approaches are single objective or weighted average of multiple objectives in model calibration. Both of these approaches are logically clear, feasible and effective for calibrating individual water related components (e.g. high flow, low flow, water quality variables) (Gupta et al., 1999; Sincock et al., 2003). Although these approaches are also applied to water related systems in which multiple objectives are considered, it is a great challenge to obtain the optimal solution among different objectives because of the degree of interaction among the many processes involved, the complexity of model structures and model uncertainty. For example, at least water quantity and quality need to be considered in river basin management, but they are interrelated (Zhang et al., 2016).

Multi-objective optimization (MOO) is an efficient and effective way to solve the issues mentioned above. This approach has become increasingly popular in water related sciences over the past 15 years (Yapo et al., 1998; Vrugt et al., 2003; Efstratiadis and Koutsoyiannis, 2010), and the applications focus on the multi-objective auto-calibration of flow components and water quality variables, respectively. The calibration strategies are divided into three categories according to the different objectives formed by (a) considering different flow components (e.g. low flow, high flow, total water volume, groundwater table, peak timing) (Liong et al., 2001; Madsen, 2003; Vrugt et al., 2003; Tang et al., 2006; Khu and Madsen, 2005; Schoups et al., 2005; Fenicia et al., 2007; Parajka et al., 2007; Shafii and De Smedt, 2009) or water quality variables (e.g. water temperature, sediment, dissolved oxygen: DO, biological oxygen demand: BOD, total phosphorus or nitrogen and chlorophyll a) (Afshar and Hamideh, 2012); (b) using different evaluation criteria (e.g. bias, mean absolute or relative errors, root mean square errors, coefficient of determination, correlation coefficient, Nash-Sutcliffe efficiency) (Gupta et al., 1998; Yapo et al., 1998; Boyle et al., 2000; Madsen, 2000; Cheng et al., 2002; Khu and Madsen, 2005; Krauße et al., 2012; Zhou et al., 2014); and (c) considering observed series from multiple sites (Bekele and Nicklow, 2007; Moussa et al., 2007; Li et al., 2010b). The popular algorithms are non-dominated evolutionary algorithms such as MOCOM-UA (Duan et al., 1992; Yapo et al., 1998), SPEA 2 (Zitzler and Thiele, 1999), MOCSEM-UA (Vrugt et al., 2003), NSGA-II (Deb et al., 2002; Kollat and Reed, 2006, MA) (Liu et al., 2012, 2014).

For the calibration of water quantity and quality, most existing cases calibrate flow components and water quality variables by multi-stage single objective optimization (i.e., step-by-step calibration). That is the flow components are calibrated first in order to provide hydrological boundaries for water quality calibration (Francos et al., 2001; Sincock et al., 2003; Bekele and Nicklow, 2007; Engel et al., 2007; Moriasi et al., 2007; Hesse et al., 2008; Paredes-Arquiola et al., 2010; Pisinaras et al., 2010; Wang et al., 2013). The main historic reason for separating the calibration was that the water quality characteristics are assumed not to affect the water flows, that is, water flows affect water quality but not vice versa. As a result, the two systems are not completely coupled during the calibration. However, due to the uncertainties of in-situ runoff data (Yen et al., 2014), the simulation errors from the calibrated hydrological components could also distort the subsequent water quality calibration and, as a result, directly affect the performance of the water quality simulation. Several studies reported that the simulations of water quality variables were usually unsatisfactory although the runoff simulation performance was acceptable due to the error accumulation caused by the uncertainties in the in-situ runoff and water quality data (Santhi et al., 2001; White and Chaubey, 2005; Kang et al., 2006; Bekele and Nicklow, 2007; Moriasi et al., 2007; Zhang et al., 2011, 2013). Moreover, due to the uncertainties in the model structure and calibrated parameter values, it is more reasonable to think that the water quality samples also infer some uncertainties in the hydrological processes (e.g. the contributions of river flow into groundwater, interflow, surface flow, low flow regimes and flood pattern) (Mroczkowski et al., 1997; Meixner et al., 2002; van Griensven and Bauwens, 2003; Aubert et al., 2013). Given that the module for water quality process is reasonable, the unacceptable simulation of water quality processes would also be caused by the uncertainty in the hydrological parameters equifinality, even if the hydrological processes are well-simulated. Nevertheless, the sources of observed information are only used to calibrate their corresponding processes and are ignored in the calibration of the other related processes. In reality, the hydrological and water quality processes take place simultaneously and inseparably, and the water quantity and quality objective functions are obviously conflicting in optimization. For example, overland flows (surface runoff, interflow and baseflow) determine both water volume and nonpoint source pollutant load into rivers (Tesoriero et al., 2009; Zhang et al., 2016). The transportation and transformation processes of pollutants occur with flow routing. Furthermore, the nutrient losses by water erosion directly disturb the soil nutrient balance, probably restrict crop growth, and then influence the transpiration of plants in the hydrological processes especially in the nutrient-limited regions. Therefore, it might be more logical and scientifically sound to calibrate all the components or modules simultaneously in the integrated water system models.

Earlier works by van Griensven and Bauwens (2003) and van Griensven and Meixner (2007) also recognized the inseparable relationship of water quantity and quality processes, and proposed a single objective auto-calibration method (a weighted average method) to aggregate the criteria of flow components and water quality variables into one single criterion. They also pointed out that the final distribution of objective functions in their global optimization criterion could be affected by an initial random sampling, and the quantity and reliability of observed data. Although this method was commonly-used in multi-site, multi-criteria or multi-period calibrations (Li et al., 2010b; Zhang et al., 2011; Ahmadi et al., 2014), the weights also need to be pre-defined and, in fact, the resulted parameter estimation was only one of many possible Pareto optimal solutions. As a generalization, we promote the simultaneous calibration of water quantity and quality by multi-objective Pareto-optimization.

The objective of this study is to explore a balanced calibration of water quantity and quality that effectively considers the interaction of different processes. We will demonstrate how to obtain the Pareto front of the sub-optimal solutions of conflicting objectives by taking full advantages of multiple observation sources. The hydrological and water quality processes are regarded as individual entities, and their observations are used for simultaneous calibration. The method is applied in the Shaying River, which is the largest and heavily polluted tributary of Huai River Basin in China. The proposed method is compared with the traditional step-by-step single objective calibration to demonstrate its 
efficiency and effectiveness in integrated water quantity and quality simulation.

\section{Study area and data processing}

Shaying River Catchment $\left(112^{\circ} 45^{\prime} \sim 113^{\circ} 15^{\prime} \mathrm{E}, 34^{\circ} 20^{\prime} \sim 34^{\circ} 34^{\prime} \mathrm{N}\right)$, the largest catchment of the Huai River Basin, China, is selected as the study area. It is an agriculturally dominated region with a drainage area of $36,651 \mathrm{~km}^{2}$ and its major landuse is dryland agriculture, accounting for over $80 \%$ of total area. Water shortage, floods and heavy pollution are the major water issues, which have significantly restricted the regional sustainable development. Fuyang Station is a key monitoring station downstream of Shaying River and controls over $90 \%$ of the whole drainage area.

The GIS, meteorological, socio-economic and agricultural management data were collated for model development, including a Digital Elevation Model (DEM), soil, landuse and crop types, daily precipitation, daily minimum and maximum air temperature, populations, fertilization (amount and timing), point source pollutant load. The observed daily runoff and intermittent observations of $\mathrm{NH}_{4}-\mathrm{N}$ concentrations at Fuyang Station were collected from 2003 to 2007. The first three year's data (from 2003 to 2005) with the mean runoff of $167.13 \mathrm{~m}^{3} / \mathrm{s}$ and mean $\mathrm{NH}_{4}-\mathrm{N}$ concentration of $3.55 \mathrm{mg} / \mathrm{L}$ were used for model calibration, and the last two year's data (from 2006 to 2007) with the mean runoff of $139.19 \mathrm{~m}^{3} / \mathrm{s}$ and mean $\mathrm{NH}_{4}-\mathrm{N}$ concentration of $3.00 \mathrm{mg} / \mathrm{L}$ were used for model validation.

Forty-six sub-basins were created using the Arc GIS platform according to the spatial distributions of landuse and geographical positions of dams, sluices and gauges (Fig. 1). The weather data series (daily precipitation, maximum and minimum air temperature) and socio-economic data (populations in urban and rural area, breeding stock of large animals and livestock, chemical fertilizer amounts) were interpolated to each sub-basin and used as the driving factors of the model. The detailed data processing procedures were presented in Zhang et al. (2016).

\section{Models and methodology}

\subsection{Integrated water system model (HEQM)}

HEQM is an integrated water system model developed by Zhang et al. (2016) for the simultaneous simulation of water related processes at basin scale, including hydrological, soil biogeochemical and water quality processes. The current version contains seven major modules (i.e. hydrological cycle module, soil biochemical module, crop growth module, soil erosion module, overland water quality module, water quality module of water bodies and dam regulation module) and a parameter analysis tool. The model framework was presented in Fig. 2. The proposed model can simulate several key water related components in a river network, such as runoff and water quality variables.

The construction of HEQM is based on the hypothesis that the cycles of water and nutrients $(\mathrm{N}, \mathrm{P}$ and $\mathrm{C})$ are inseparable and act as the critical linkages among all the modules (Fig. 3). In this study, we only calibrate for water quantity and quality objectives. These are grouped into the "yield" and "migration" processes. The yield

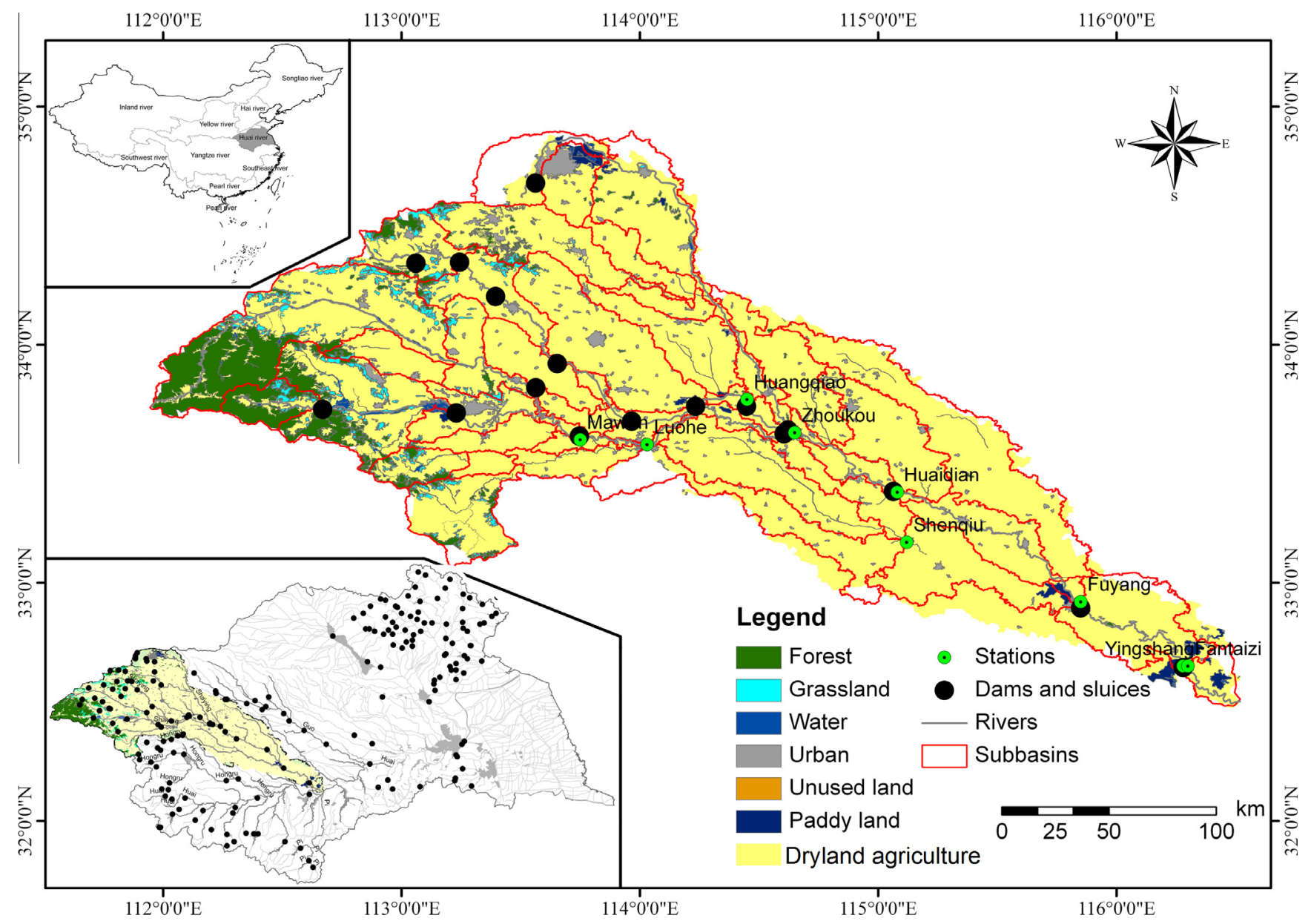

Fig. 1. The research area and sub-basin delineation. 


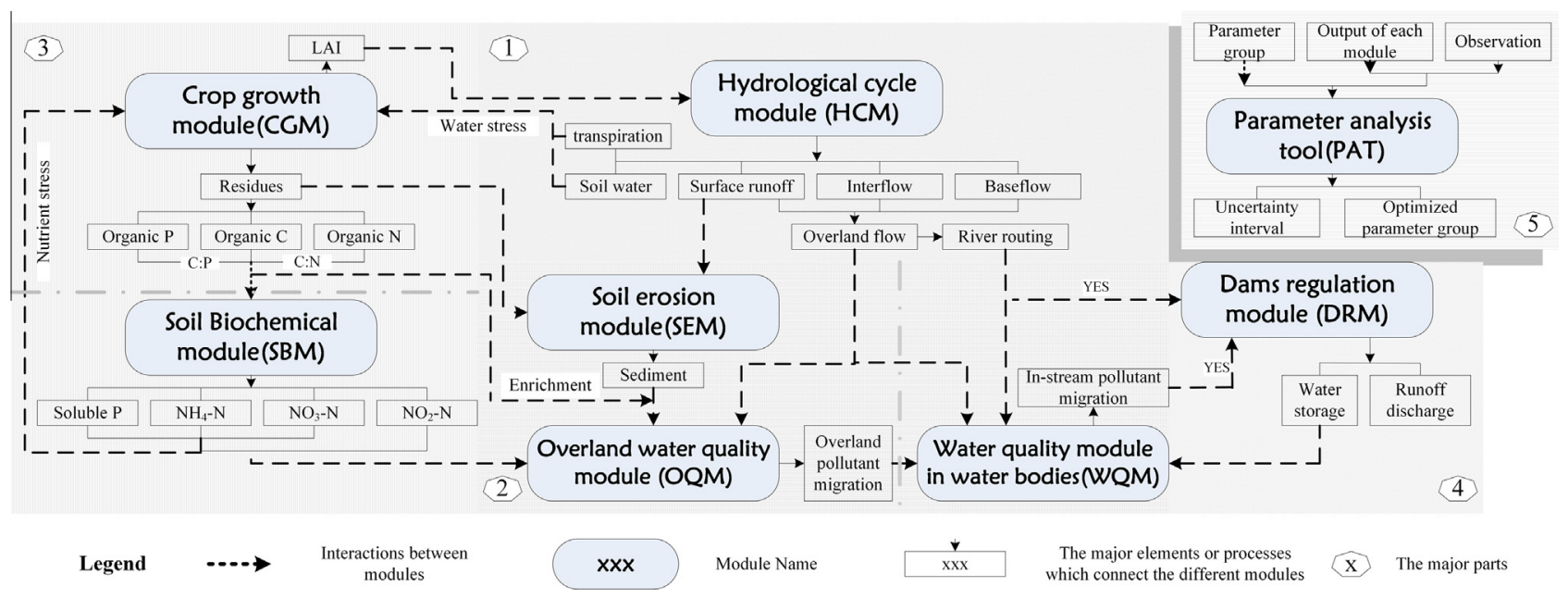

Fig. 2. The framework of HEQM and its interactions among modules.

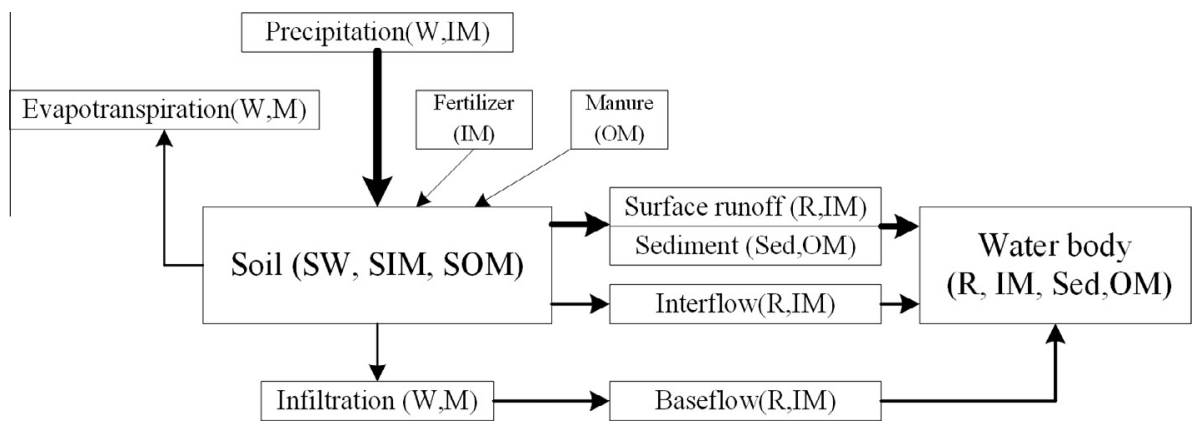

Fig. 3. The interaction of hydrological and environmental processes in HEQM.

processes of overland runoff and nonpoint pollutant load are briefly described as

$$
\left\{\begin{array}{l}
R=P(R)-E(R)-I(R)-V S(R) \\
M=M_{\text {in }}+M_{\text {org }} \\
\quad=F(M)+P(M)-E(M)-I(M)-V S(M)-D_{\text {yield }}(M) \\
D_{\text {yield }}(M)=f_{d_{-} \text {yield }}(S W, S T, S P)
\end{array}\right.
$$

where $R$ is runoff; $M$ is the pollutant including inorganic matter $\left(M_{i n}\right)$ and organic matter $\left(M_{\text {org }}\right)$, respectively; $F(M)$ is agricultural fertilizing processes; $P(\cdot), E(\cdot)$ and $I(\cdot)$ are the processes of precipitation, evapotranspiration and infiltration, respectively; VS(.) is the variation of water and matter in the soil layer; $D_{\text {yield }}(\cdot)$ is the matter degradation in the soil layer, which has a complicated nonlinear relation $f_{d \_ \text {yield }}(\cdot)$ with the soil related factors, such as soil water $(S W)$, soil temperature (ST) and soil properties (SP) (Xia et al., 2005).

The overland or instream migration processes of runoff and nonpoint pollutant load are briefly described as

$$
\left\{\begin{array}{l}
R^{\prime}=f_{m i g}^{R}(R) \\
M^{\prime}=f_{m i g}^{\text {in }}\left(M_{\text {in }}, R\right)+f_{\text {mig }}^{\text {org }}\left(M_{\text {org }}, S e d\right)-D_{\text {mig }}(M)+P L(M) \\
D_{\text {mig }}(M)=f_{d \_m i g}(R, L U C C, O S, O L, W T, S L)
\end{array}\right.
$$

where $R$ and $M$ are the runoff and pollutant after migration, respectively; Sed is the sediment yield; $f_{\text {mig }}^{R}(\cdot)$ is the runoff routing process, which has an exponential relationship with the migration time; $f_{m i g}^{\text {in }}(\cdot)$ and $f_{\text {mig }}^{\text {org }}(\cdot)$ are the migration processes of $M_{\text {in }}$ and $M_{\text {org }}$, respectively, and have linear relationships with the runoff routing; $D_{\text {mig }}(\cdot)$ is the pollutant degradation and loss during the overland or instream processes, which has a complicated nonlinear relation $f_{d \_m i g}(\cdot)$ with runoff, water temperature $(W T)$, landuse type (LUCC), overland slope $(O S)$ and length $(O L)$, as well as stream length $(S L)$ (Zhang et al., 2016).

\subsection{Multi-objective auto-calibration algorithm}

Nondominated sorting genetic algorithm II (NSGA-II), an improved version of NSGA (Srinivas and Deb, 1994), was proposed by Deb et al. (2002) to effectively solve the conflicts among different objectives and obtain a set of trade-off optimal solutions (Pareto front solution). This algorithm contains a fast non dominated procedure in an elitist-preserving approach and crowed comparison parameterless niching operator. It alleviates the criticism of computational complexity, lack of elitism and the need for specifying a sharing parameter in other multi-objective evolutionary algorithms.

Currently, NSGA-II has been considered as a landmark in the field of evolutionary multi-objective optimization (Coello, 2006) and widely applied in economic and finance (Tapia and Coello, 2007), electric power dispatch (Abido, 2006), engineering shape design (Deb and Goel, 2001), water resources and environmental management (Suen and Eheart, 2006; Maringanti et al., 2009), numerical model auto-calibration like hydrological model (Khu and Madsen, 2005;Tang et al., 2006;Fenicia et al., 2007;Shafii and De Smedt, 2009), water quality model (Bekele and Nicklow, 2007), and so on.

\subsection{Integration between HEQM and NSGA-II}

\subsubsection{Integration procedures}

The source code of NSGA-II was downloaded from the website of Kanpur Genetic Algorithms Laboratory (http://www.iitk.ac.in/ 
kangal/index.shtml) and was coupled with HEQM by interchanging the parameter value sets and their corresponding function values, respectively. The framework is shown in Fig. 4 and the procedures are presented below.

(1) Pre-determine the hydrological and water quality parameters of HEQM to be estimated as well as their value ranges by, for example, sensitivity analysis;

(2) Randomly generate a large number of parameter sets (parent population with size of $N$ ) of HEQM by NSGA-II.

(3) Simulate the runoff and water quality processes by HEQM for each parameter set and calculate the values of their objective functions.

(4) Sort the nondomination ranks of the objective values and their corresponding parameter sets by the fast nondominated sorting procedure of NSGA-II.

(5) Generate the child population (size: $N$ ) by the critical processes of genetic algorithm (i.e. selection, crossover, mutation) and calculate the values of their objective functions of the child population by HEQM.

(6) Sort the nondomination ranks of the objective values and their corresponding parameter sets and combine with the parent population (size: $2 \mathrm{~N}$ ).

(7) Estimate the crowed distance of each objective value and compare between different objective values for the elitism of a new parent population (size: $N$ ) and a uniformly spread out Pareto front.

(8) Check the convergence statistics and the iterations. If the convergence criteria or maximum iterations are satisfied, output the parameter sets and Pareto front solution; otherwise, return to step 5 .

There are seven main control parameters in NSGA-II, i.e., the number of objectives, the number of parameters to be estimated, the number of constraints, the population size, the maximum number of iterations, the cross-over probability and its type (1: simple point or 2: uniform), the mutation probability. The numbers of objectives, parameters and constraints were determined by users while the default values of other parameters are set as 100 , $200,0.90,1$ and 1.0, respectively. In this paper, two objectives were set because runoff and water quality processes were calibrated simultaneously, and the estimated parameters and constraints were the selected sensitive parameters of HEQM and their ranges, respectively.

For ease of discussion, the Pareto fronts were divided into three sections according to the elastic coefficient (ECQ) of model performance between water quantity and quality, defined as

$E C Q=\frac{\Delta P_{C}}{P_{C}} / \frac{\Delta P_{Q}}{P_{Q}}$

where $P_{Q}$ and $P_{C}$ are the evaluated index values of model performance of water quantity and quality, respectively; $\Delta P_{Q}$ and $\Delta P_{C}$ are the variation ranges of simulation performance of water quantity and quality, respectively. The ECG should be always negative because of a tradeoff between the simulation performance of water quantity and quality in the Pareto front, causing the opposite signs of $\Delta P_{Q}$ and $\Delta P_{C}$.

The dominated section for water quality simulation improvement was the segment with large negative $E C Q$ the trade-off section between water quantity and quality simulation improvement was the segment with moderate ECQ and the dominated section for water quantity improvement was the segment with small negative $E C Q$.

As a comparison, NSGA-II was also applied to the parameter calibration of hydrological and water quality separately by the step-by-step approach, that is, the hydrological parameters were calibrated first and the water quality related parameters were

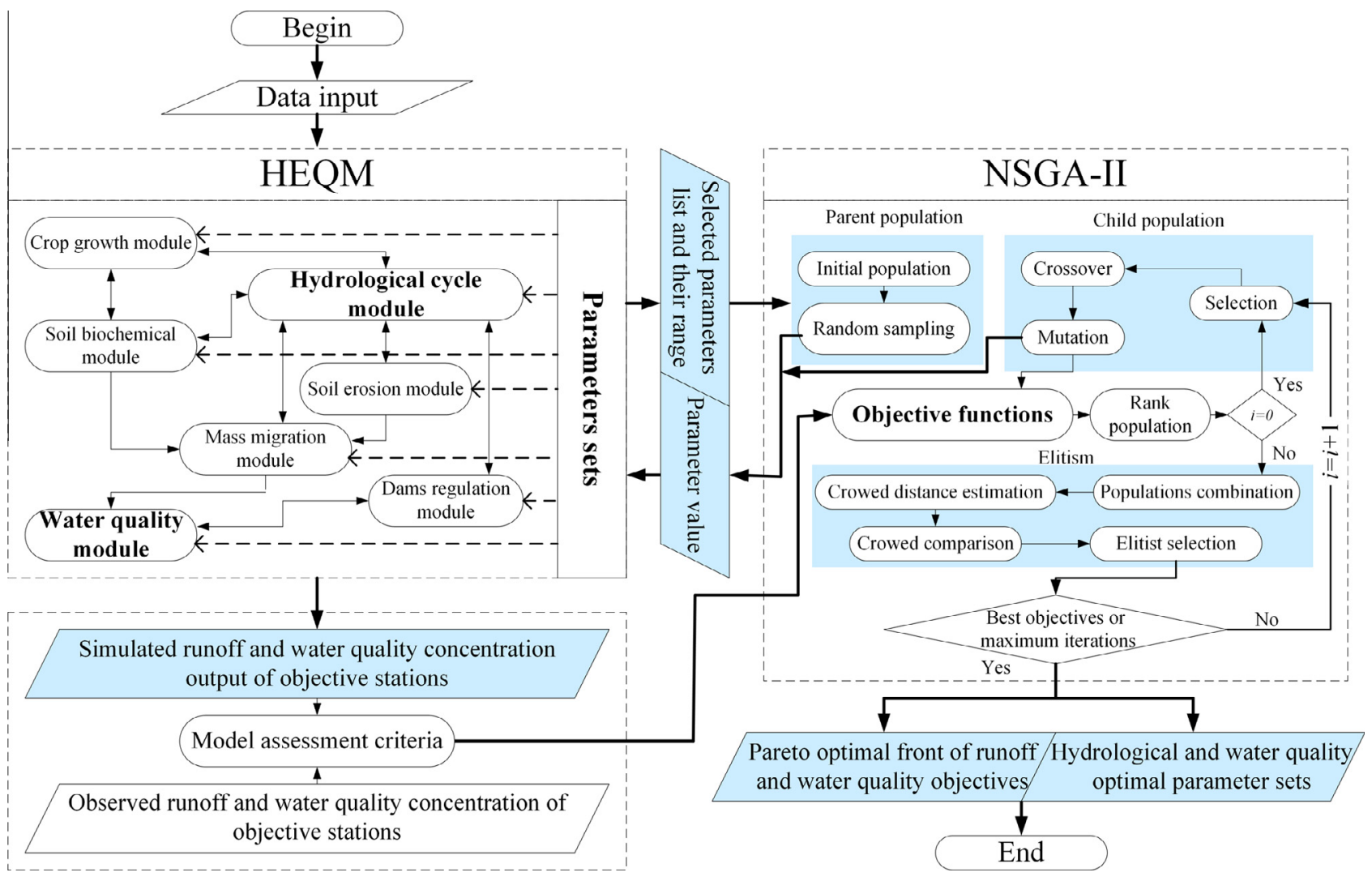

Fig. 4. The flow chart of NSGA-II for the simultaneous calibration of water quantity and quality. 
calibrated conditionally on the values of the optimal calibrated hydrological parameter. The step-by-step procedure was traditional and widely-used in the water quantity and quality calibration of distributed watershed models.

\subsubsection{The objective functions for calibration}

The objective of model calibration is to make the simulations best match the observations where the overall agreement is quantified by model evaluation criteria. The root mean square error (RMSE) is straightforward and widely used to assess the model performance of runoff, water quality variables and others. The objective function is formulated as

$R M S E=\sqrt{\sum_{i=1}^{N}\left(O_{i}-S_{i}\right)^{2} / N}$

where $N$ is the number of the series, $O_{i}$ and $S_{i}$ are the $i$ th observed and simulated values, respectively. For the single objective calibration, the aim is to find the optimal parameter values which minimize the RMSE value.

For the multiple objective functions (i.e., the RMSEs of runoff and water quality series), the aim was to find so-called Pareto optimal in which none of the objective functions can be improved in value without worsening some of the other objective values. In our case study, the objective function was expressed as

$$
\begin{aligned}
f_{\text {multi-ob }}= & \operatorname{minimize}\left\{R M S E_{-Q}, R M S E_{-}\right\} \\
& \text {subject to } \operatorname{par}(Q, C)_{\min } \leqslant \operatorname{par}(Q, C) \leqslant \operatorname{par}(Q, C)_{\max }
\end{aligned}
$$

where $f_{\text {multi-ob }}$ is the multi-objective function; $R M S E_{-Q}$ and $R M S E_{-C}$ are the RMSE of simulated runoff and water quality indicators, respectively. $\operatorname{par}(Q, C), \operatorname{par}(Q, C)_{\min }$ and $\operatorname{par}(Q, C)_{\max }$ are the parameter lists of water quantity and quality, their maximum and minimum limits, respectively.

Alternatively, the traditional step-by-step approach for water quantity and quality calibration was as follow.

Step 1: Water quantity parameters were calibrated first using the objective function

$$
\begin{aligned}
f_{\text {single-Q }}= & \operatorname{minimize}\left\{R M S E_{-Q}\right\} \\
& \text { subject to } \operatorname{par}(Q)_{\min } \leqslant \operatorname{par}(Q) \leqslant \operatorname{par}(Q)_{\max }
\end{aligned}
$$

Step 2: Water quality parameters were then calibrated using the objective function

$$
\begin{aligned}
f_{\text {single-C }}= & \text { minimize }\left\{R M S E_{-}\right\} \\
& \text {subject to } \operatorname{par}(C)_{\min } \leqslant \operatorname{par}(C) \leqslant \operatorname{par}(C)_{\max } \\
& \text { with } \operatorname{par}(Q)=\operatorname{par}(Q)_{\text {opt }}
\end{aligned}
$$

with the water quantity parameters fixed at the calibrated values from Step 1 , where $f_{\text {single- } Q}$ and $f_{\text {single- } C}$ are the single objective function of water quantity and quality, respectively; $\operatorname{par}(Q)_{o p t}$ are the optimal parameter lists of water quantity. The number of objectives in NSGA-II is one for each step and NSGA-II will be performed twice.

\subsection{Model evaluation}

In addition to the objective RMSE, three more statistics were also used to evaluate the model performance, including normalized bias (Nbias), correlation coefficient $(r)$ and coefficient of efficiency (NS) (Nash and Sutcliffe, 1970) defined as

Normalized bias:

Nbias $=\frac{\sum_{i=1}^{N}\left(O_{i}-S_{i}\right)}{\sum_{i=1}^{N} O_{i}}$

Correlation coefficient:

$r=\frac{\sum_{i=1}^{N}\left(O_{i}-\bar{O}\right) \cdot\left(S_{i}-\bar{S}\right)}{\sqrt{\sum_{i=1}^{N}\left(O_{i}-\bar{O}\right)^{2} \cdot \sum_{i=1}^{N}\left(S_{i}-\bar{S}\right)^{2}}}$

Coefficient of efficiency:

$N S=1-\frac{\sum_{i=1}^{N}\left(O_{i}-S_{i}\right)^{2}}{\sum_{i=1}^{N}\left(O_{i}-\bar{O}\right)^{2}}$

where $O_{i}$ and $S_{i}$ are the $i$ th observed and simulated value, respectively; $\bar{O}$ and $\bar{S}$ are the average observed and simulated value, respectively. The criteria are summarized in Table 1 according to Santhi et al. (2001) and Moriasi et al. (2007). In the situation of conflicting performance ratings among these three indices, the overall model performance is determined conservatively by the worst rating.

\section{Results and discussion}

\subsection{Sensitive parameters selection}

There are 182 parameters that control the hydrological, ecological and water quality processes of HEQM (Zhang et al., 2016). The parameter sensitivity analysis was carried out using a global sensitivity analysis tool (LH-OAT: Latin Hypercube One factor At a Time) in order to increase the optimizing efficiency (van Griensven et al., 2006). Nine and twenty-eight distributed sensitive parameters were detected to have close relationships with runoff and $\mathrm{NH}_{4}-\mathrm{N}$ concentration, respectively (Table 2). The sensitive parameters for runoff simulation were soil related parameters $\left(W_{f c}: 32.73 \%\right.$, $W_{\text {sat }}: 11.68 \%, K_{r}: 9.55 \%$ and $\left.K_{\text {sat }}: 0.33 \%\right)$, surface runoff yield parameters $\left(g_{1}: 7.30 \%\right.$ and $\left.g_{2}: 10.54 \%\right)$, baseflow parameters $\left(K_{g}: 2.91 \%\right.$ and $\left.T_{g}: 1.74 \%\right)$ and evapotranspiration parameter ( $\left.K_{E T}: 23.21 \%\right)$. The sensitive parameters for $\mathrm{NH}_{4}-\mathrm{N}$ concentration simulation were divided into six hydrological parameters (59.28\%), 11 nitrogen parameters (22.46\%), five parameters of COD (Chemical Oxygen Demand) (13.00\%) and six soil carbon parameters (0.17\%).

The key hydrological processes (i.e., soil water, surface runoff and evapotranspiration) explained $26.13 \%, 22.45 \%$ and $10.71 \%$ of

\begin{tabular}{|c|c|c|c|c|}
\hline \multirow[t]{2}{*}{ Performance rating } & \multicolumn{2}{|l|}{ Bias } & \multirow[t]{2}{*}{$r$} & \multirow[t]{2}{*}{ NS } \\
\hline & Runoff & $\mathrm{NH}_{4}-\mathrm{N}$ concentration & & \\
\hline Very good & {$[-0.10,0.10]$} & {$[-0.15,0.15]$} & {$[0.85,1.00]$} & {$[0.75,1.00]$} \\
\hline Good & $(0.10,0.15]$ or $[-0.15,-0.10)$ & $(0.15,0.30]$ or $[-0.30,0.15)$ & {$[0.80,0.85)$} & {$[0.60,0.75)$} \\
\hline Satisfactory & $(0.15,0.25]$ or $[-0.25,-0.15)$ & $(0.30,0.50]$ or $[-0.50,-0.30)$ & {$[0.75,0.80)$} & {$[0.50,0.60)$} \\
\hline Unsatisfactory & $(0.25,+\infty)$ or $(-\infty,-0.25)$ & $(0.50,+\infty)$ or $(-\infty,-0.50)$ & $(-\infty, 0.75)$ & $(-\infty, 0.50)$ \\
\hline
\end{tabular}
the variation of $\mathrm{NH}_{4}-\mathrm{N}$ observations. The related parameters were $W_{f c}(11.10 \%), W_{\text {sat }}(11.83 \%)$ and $K_{r}(3.20 \%)$ for the soil water; $g_{1}$ (10.34\%) and $g_{2}(12.11 \%)$ for the surface runoff yield and $K_{E T}$ $(10.71 \%)$ for the evapotranspiration. Specifically, overland flow

Table 1

Model performance criteria for runoff and $\mathrm{NH}_{4}-\mathrm{N}$ concentration of HEQM 
Table 2

Sensitive parameters and their ranges, and relative importance for runoff and $\mathrm{NH}_{4}-\mathrm{N}$ concentration.

\begin{tabular}{|c|c|c|c|c|c|}
\hline Name & Min & Max & Definition & Relative importance for $\mathrm{Q}$ & Relative importance for $\mathrm{NH}_{4}-\mathrm{N}$ \\
\hline$W_{f c}$ & 0.20 & 0.45 & Field capacity of soil & 32.73 & 11.0996 \\
\hline$W_{\text {sat }}$ & 0.45 & 0.75 & Saturation moisture capacity of soil & 11.68 & 11.8310 \\
\hline$g_{1}$ & 0.00 & 3.00 & Basic runoff coefficient & 7.30 & 10.3375 \\
\hline$g_{2}$ & 0.00 & 3.00 & Influence coefficient of soil moisture & 10.54 & 12.1095 \\
\hline$K_{E T}$ & 0.00 & 3.00 & Adjustment factor of evapotranspiration & 23.21 & 10.7075 \\
\hline$K_{r}$ & 0.00 & 1.00 & Interflow yield coefficient & 9.55 & 3.1951 \\
\hline$T_{g}$ & 1.00 & 100. & Delay time for aquifer recharge & 1.74 & - \\
\hline$K_{g}$ & 0.00 & 1.00 & Baseflow yield coefficient & 2.91 & - \\
\hline$K_{\text {sat }}^{b}$ & 0.00 & 120. & Steady state infiltration rate of soil & 0.33 & - \\
\hline$K_{\text {set }}\left(\mathrm{NH}_{4}\right)$ & 0.00 & 100. & Settling rate of $\mathrm{NH}_{4}-\mathrm{N}$ at $20^{\circ} \mathrm{C}$ in reservoir & - & 14.1678 \\
\hline$R_{d}(\mathrm{COD})$ & 0.02 & 3.40 & COD deoxygenation rate at $20^{\circ} \mathrm{C}$ in channel & - & 6.6208 \\
\hline$K_{d}\left(\mathrm{NH}_{4}\right)$ & 0.10 & 1.00 & Bio-oxidation rate of $\mathrm{NH}_{4}-\mathrm{N}$ at $20^{\circ} \mathrm{C}$ in reservoir & - & 4.5072 \\
\hline$R_{\text {set }}(\mathrm{COD})$ & -0.36 & 0.36 & COD settling rate at $20^{\circ} \mathrm{C}$ in channel & - & 3.5971 \\
\hline$K_{d}(\mathrm{COD})$ & 0.02 & 3.40 & COD deoxygenation rate at $20^{\circ} \mathrm{C}$ in reservoir & - & 2.1214 \\
\hline$R_{d}\left(\mathrm{NH}_{4}\right)$ & 0.10 & 1.00 & Bio-oxidation rate of $\mathrm{NH}_{4}-\mathrm{N}$ at $20^{\circ} \mathrm{C}$ in channel & - & 1.9710 \\
\hline$K_{\text {set }}(\mathrm{COD})$ & 0.00 & 269 & Settling rate of COD at $20^{\circ} \mathrm{C}$ in reservoir & - & 0.6128 \\
\hline$K_{d}(\operatorname{orgN})$ & 0.20 & 0.40 & Hydrolysis rate of organic $\mathrm{N}$ to $\mathrm{NH}_{4}-\mathrm{N}$ at $20^{\circ} \mathrm{C}$ in reservoir & - & 0.5609 \\
\hline$R_{d}(\operatorname{orgN})$ & 0.20 & 0.40 & Hydrolysis rate of organic $\mathrm{N}$ to $\mathrm{NH}_{4}-\mathrm{N}$ at $20^{\circ} \mathrm{C}$ in channel & - & 0.5584 \\
\hline$R_{\text {set }}\left(\mathrm{NH}_{4}\right)$ & -50.0 & 50 & $\mathrm{NH}_{4}-\mathrm{N}$ settling rate at $20^{\circ} \mathrm{C}$ in channel & - & 0.2848 \\
\hline$K_{\text {scu }}\left(\mathrm{NH}_{4}\right)$ & 0.00 & 69 & Resuspension rate of $\mathrm{NH}_{4}-\mathrm{N}$ at $20^{\circ} \mathrm{C}$ in reservoir & - & 0.1951 \\
\hline$R_{\text {set }}(\operatorname{orgN})$ & 0.001 & 0.10 & Organic $\mathrm{N}$ settling rate at $20^{\circ} \mathrm{C}$ in channel & - & 0.0841 \\
\hline$K_{d}\left(\mathrm{NO}_{2}\right)$ & 0.20 & 2.00 & Bio-oxidation rate of $\mathrm{NO}_{2}-\mathrm{N}$ to $\mathrm{NO}_{3}-\mathrm{N}$ at $20^{\circ} \mathrm{C}$ in reservoir & - & 0.0627 \\
\hline$K_{\text {scu }}(\mathrm{COD})$ & 0.00 & 269 & Resuspension rate of COD $20^{\circ} \mathrm{C}$ in reservoir & - & 0.0481 \\
\hline$\mu_{C L A Y}$ & 0.01 & 1.00 & Clay content reduction factor & - & 0.0408 \\
\hline$K_{1}$ & 0.01 & 1.00 & Decomposition rate of labile $C$ pool & - & 0.0377 \\
\hline$S$ & 0.01 & 1.00 & Ratio of labile organic C pool in the total biomass & - & 0.0371 \\
\hline$R_{d}\left(\mathrm{NO}_{2}\right)$ & 0.20 & 2.00 & Bio-oxidation rate of $\mathrm{NO}_{2}-\mathrm{N}$ to $\mathrm{NO}_{3}-\mathrm{N}$ at $20^{\circ} \mathrm{C}$ in channel & - & 0.0332 \\
\hline$M_{N O 3}$ & 0.00 & 1.00 & Maintenance coefficient of $\mathrm{NO}_{3}-\mathrm{N}$ in soil & - & 0.0309 \\
\hline$k m_{s c}$ & 0.01 & 1.00 & Decomposition ratio of stable organic $C$ in microbial biomass pool & - & 0.0220 \\
\hline$k m_{c l}$ & 0.01 & 1.00 & Decomposition ratio of labile organic $\mathrm{C}$ pool in microbial biomass pool & - & 0.0150 \\
\hline$k r_{c v l}$ & 0.01 & 1.00 & Decomposition ratio of very labile organic $C$ pool in residue pool & - & 0.0143 \\
\hline \multicolumn{4}{|c|}{ Total relative importance } & 100.00 & 94.90 \\
\hline
\end{tabular}

determined the total nonpoint source pollutant loads into rivers, and runoff affected the degradation and settling processes of pollutants in water bodies (van Griensven and Bauwens, 2003). Thus, the observed water quality series also implied useful information about related hydrological processes, which could be used to calibrate related hydrological parameters (i.e., $W_{f c}, W_{s a t}, K_{r}, g_{1}, g_{2}$ and $K_{E T}$ in our study). In particular, the importance of $W_{s a}, g_{1}$ and $g_{2}$ parameters for $\mathrm{NH}_{4}-\mathrm{N}$ concentration simulation was even greater than that for runoff simulation. More information about hydrological processes could be obtained from water quality observations whereas, the step-by-step calibration could not take full advantages of all the calibrated components.

\subsection{Pareto fronts of calibration}

The final 70 solutions were identified from 20,000 solution sets to form the Pareto front based on the RMSE objectives of runoff and $\mathrm{NH}_{4}-\mathrm{N}$ concentration (Fig. 5a). The RMSE values of runoff (RMSE_Q) were from $159.460\left(Q_{\min }\right)$ to $276.833 \mathrm{~m}^{3} / \mathrm{s}\left(Q_{\max }\right)$, while those of $\mathrm{NH}_{4}-\mathrm{N}$ concentration (RMSE_C) were from $2.359\left(C_{\min }\right)$ to $2.713 \mathrm{mg} / \mathrm{L}\left(C_{\max }\right)$ (Table A1). All of these errors were probably from the uncertainty of model structure. The simulation performances of runoff varied from the unsatisfactory to very good ratings and those of $\mathrm{NH}_{4}-\mathrm{N}$ were from the satisfactory to good ratings. The $\mathrm{NH}_{4}-\mathrm{N}$ simulations were not as good as the runoff simulations due to the more complicated yield and migration mechanism of $\mathrm{NH}_{4}-\mathrm{N}$ and its discontinuous observations. The Pareto front was divided into three sections according to the elastic coefficient (ECQ) of model performance between $\mathrm{NH}_{4}-\mathrm{N}$ and $Q$ (Fig. 5b), i.e., the dominated section for $\mathrm{NH}_{4}-\mathrm{N}$ improvement, the trade-off section between $\mathrm{NH}_{4}-\mathrm{N}$ and $Q$ and the dominated section for $Q$ improvement. The Pareto front provided stake-holders flexibilities to choose the satisfactory solutions based on specific requirements.
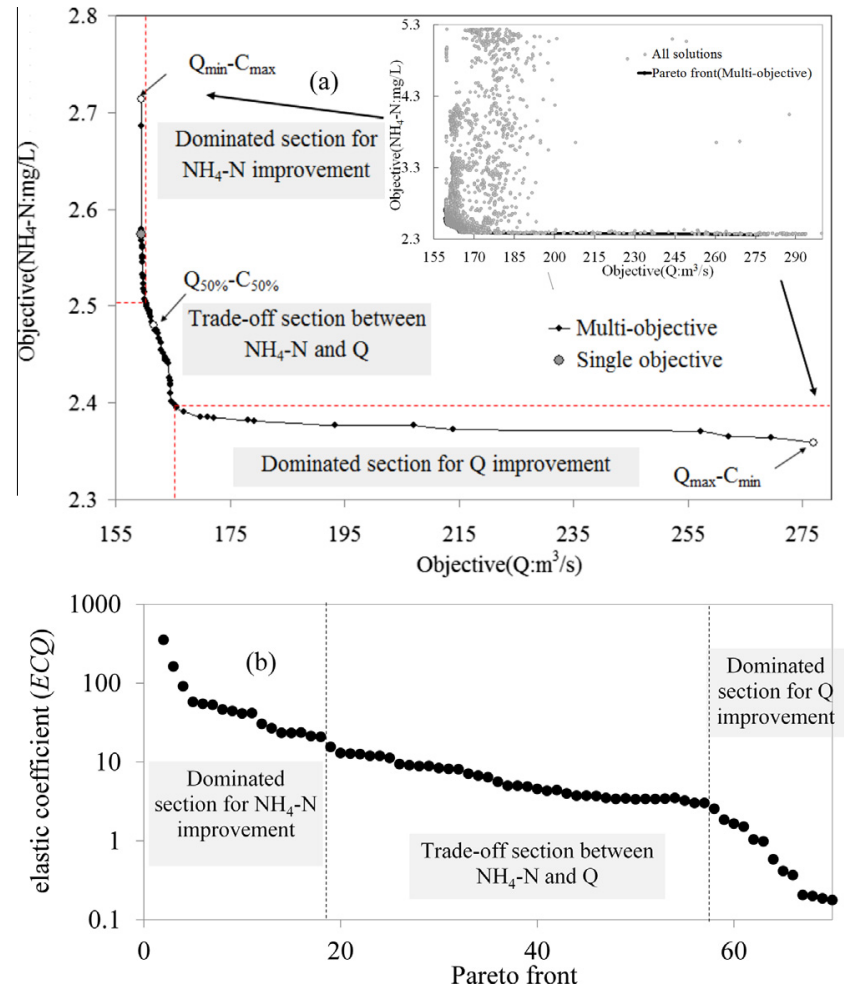

Fig. 5. The objective function values, and the elastic coefficients along the Pareto front.

In the dominated section for $\mathrm{NH}_{4}-\mathrm{N}$ improvement, RMSE_C decreased by $7.60 \%$ from 2.713 to $2.507 \mathrm{mg} / \mathrm{L}$, while RMSE_Q increased by only $0.36 \%$ from 159.460 to $160.041 \mathrm{~m}^{3} / \mathrm{s}$. The ECQ 
values ranged from -352.91 to -20.83 with the mean of -65.64 . For $\mathrm{NH}_{4}-\mathrm{N}$ simulation, the $r$ and $\mathrm{NS}$ values increased slightly from 0.786 to 0.795 and from 0.503 to 0.576 , respectively and all of them were in the satisfactory rating. The Nbias improved obviously from 0.249 (good) to 0.150 (very good) (Fig. 6). For runoff simulation, the evaluation criteria were still in the very good rating and only the Nbias changed from 0.007 to 0.040 . Thus, the small losses of $Q$ simulation performance obviously improved $\mathrm{NH}_{4}-\mathrm{N}$ simulation, especially for the Nbias.

In the trade-off section between $\mathrm{NH}_{4}-\mathrm{N}$ and $Q, R M S E_{-} C$ decreased by $3.37 \%$ from 2.505 to $2.395 \mathrm{mg} / \mathrm{L}$, while RMSE_Q increased by $4.39 \%$ from 160.249 to $165.644 \mathrm{~m}^{3} / \mathrm{s}$. The ECQ values ranged from -15.51 to -3.02 with the mean of -6.56 . Both $\mathrm{NH}_{4}-\mathrm{N}$ and runoff simulations changed slightly. For runoff simulation, the values of Nbias, $r$ and NS changed from 0.032 to 0.078 , from 0.901 to 0.896 , and from 0.81 to 0.797 , respectively. All of these criteria were still in the very good rating. For $\mathrm{NH}_{4}-\mathrm{N}$ simulation, the values of Nbias, $r$ and NS changed from 0.151 (very good) to 0.056 (very good), from 0.794 (satisfactory) to 0.796 (satisfactory), from 0.576 (satisfactory) to 0.613 (good), respectively. The compromising optimal solution between $\mathrm{NH}_{4}-\mathrm{N}$ and runoff simulation appeared in this section.

In the dominated section for $Q$ improvement, RMSE_C increased by $1.75 \%$ from 2.359 to $2.390 \mathrm{mg} / \mathrm{L}$, while $R M S E \_Q$ decreased by $68.08 \%$ from 276.83 to $166.87 \mathrm{~m}^{3} / \mathrm{s}$. The ECQ values ranged from -2.56 to -0.18 with the mean of -0.90 . Thus, the runoff simulation was obviously improved from the unsatisfactory rating to the good rating, although $\mathrm{NH}_{4}-\mathrm{N}$ simulation became a little weaker. For runoff simulation, the values of Nbias, $r$ and NS changed from -0.103 (good) to 0.077 (very good), from 0.837 (good) to 0.895 (very good), from 0.432 (unsatisfactory) to 0.797 (very good), respectively. For $\mathrm{NH}_{4}-\mathrm{N}$ simulation, these three evaluation criteria changed slightly from 0.080 (very good) to 0.025 (very good), from 0.818 (good) to 0.791 (satisfactory) and from 0.624 (good) to 0.614 (good), respectively.

Fig. 7 presented the comparisons between the observations and simulations of runoff and $\mathrm{NH}_{4}-\mathrm{N}$ concentration with extreme objective function values in the Pareto front. When RMSE_Q had the minimum $\left(159.460 \mathrm{~m}^{3} / \mathrm{s}\right)$ and $R M S E_{-} C$ had the maximum value $(2.713 \mathrm{mg} / \mathrm{L})$ (named as: $\left.Q_{\min }-C_{\max }\right)$, the simulated runoff matched well with the observations. All of these three indices were in the very good performance rating, i.e., 0.070 for Nbias, 0.901 for $r$ and 0.812 for $\mathrm{NS}$. However, the $\mathrm{NH}_{4}-\mathrm{N}$ concentration was typically underestimated, particularly before the flood season (January to

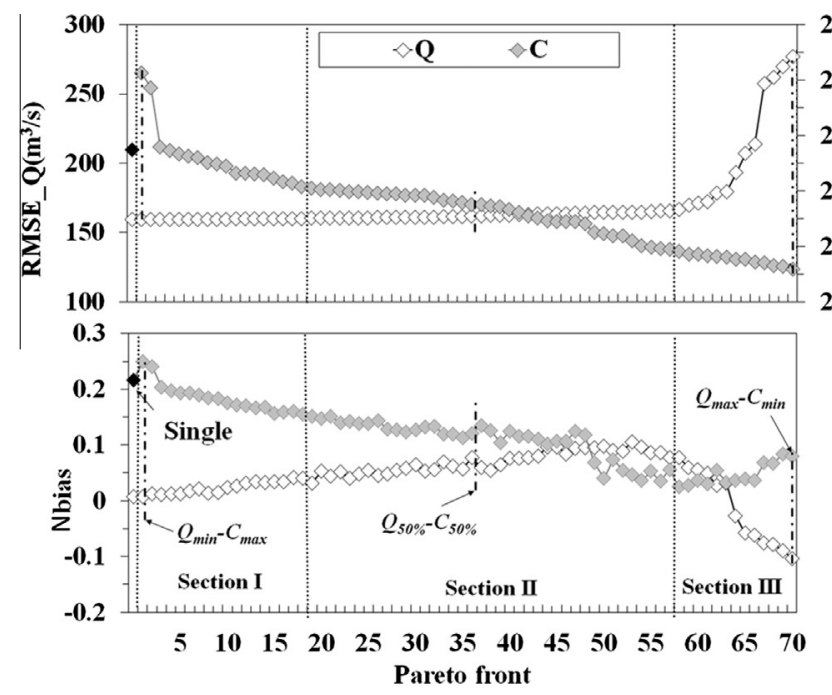

May). The performance was good for Nbias (0.249), satisfactory for both $r(0.786)$ and $N S(0.503)$, respectively. When RMSE_C got the minimum $(2.359 \mathrm{mg} / \mathrm{L})$ and $R M S E_{-} Q$ was the maximum value $\left(276.833 \mathrm{~m}^{3} / \mathrm{s}\right)$ (named as: $\left.Q_{\max }-C_{\min }\right)$, the simulated $\mathrm{NH}_{4}-\mathrm{N}$ concentration was obviously improved, especially the Nbias in the very good rating (0.080). In addition, the other two indices were in the good rating, viz., $0.818(r)$ and $0.624(N S)$, respectively. However, the concentrations were still underestimated in March and April. For the runoff simulation, it was underestimated in the non-flood season (October to June), but obviously overestimated in the flood season (July to September). The performance was good for Nbias $(-0.103)$ and $r(0.837)$, but unsatisfactory for $N S(0.432)$ due to the mismatch of peak flow. The overall performance for runoff simulation was in the unsatisfactory rating. Thus, runoff and $\mathrm{NH}_{4}-\mathrm{N}$ calibrations were highly mutually affected and the trade-off was clear. The simulation of $\mathrm{NH}_{4}-\mathrm{N}$ concentration was quite sensitive to low flow variation.

\subsection{Model validation}

Along the Pareto front, the RMSE_Q values ranged from 113.605 to $177.244 \mathrm{~m}^{3} / \mathrm{s}$, while the RMSE_C values ranged from 1.913 to $2.162 \mathrm{mg} / \mathrm{L}$ in the validation period. The variations of both $R M S E \_Q$ and $R M S E_{-} C$ were generally similar with those in the calibration period except the RMSE_C in the dominated section for $Q$ improvement (Fig. 8). All of these errors were also probably caused by the uncertainty of model structure. The simulation performances of runoff varied from the satisfactory to good ratings and those of $\mathrm{NH}_{4}-\mathrm{N}$ were from the unsatisfactory to satisfactory ratings. The $\mathrm{NH}_{4}-\mathrm{N}$ simulations were also not as good as the runoff simulations.

In the dominated section for $\mathrm{NH}_{4}-\mathrm{N}$ improvement, the performances of runoff simulation were in the satisfactory rating, although the $r$ and NS values were in the very good rating. The performances of $\mathrm{NH}_{4}-\mathrm{N}$ simulation were in the unsatisfactory rating, although the Nbias values were in the very good rating. The values of $r$ and NS increased continuously from 0.691 to 0.723 and from 0.434 to 0.465 , respectively. In the trade-off section between $\mathrm{NH}_{4}-\mathrm{N}$ and $\mathrm{Q}$, all the $r$ and $N S$ values of the runoff simulation were also in the very good rating and the Nbias values were still in the satisfactory rating, varying from 0.175 to 0.239 . However, all the criteria of $\mathrm{NH}_{4}-\mathrm{N}$ simulation improved significantly and the performances shifted from the unsatisfactory to satisfactory ratings. The overall optimal between $Q$ and $\mathrm{NH}_{4}-\mathrm{N}$ also appeared in this section. In the dominated section for $Q$ improvement, the performances of

Fig. 6. The variation of all the evaluation criteria (RMSE, Nbias, $r$ and NS) along the Pareto front during the calibration period. 

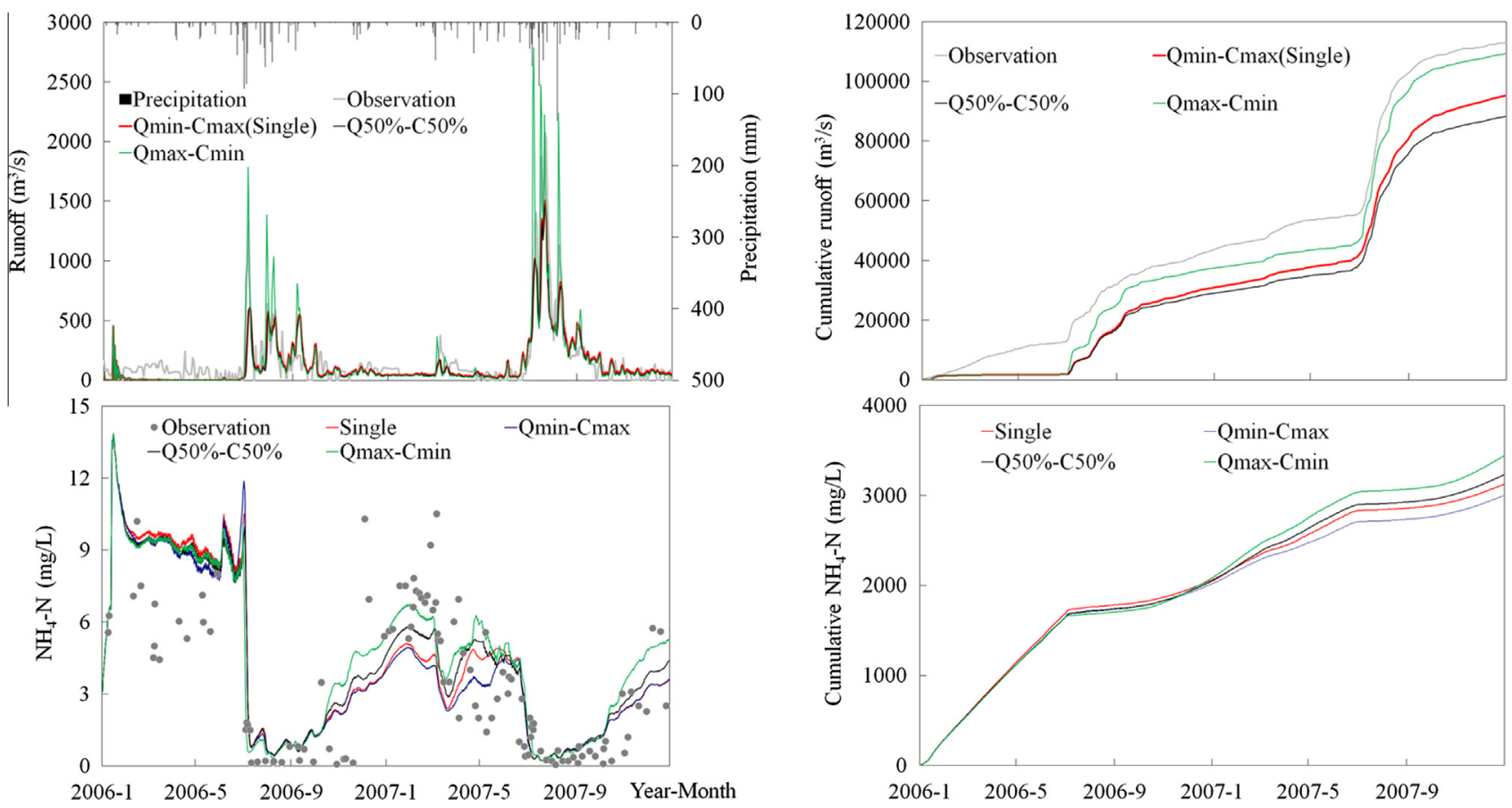

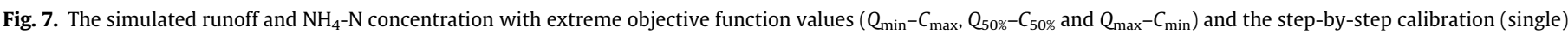
during the calibration period.
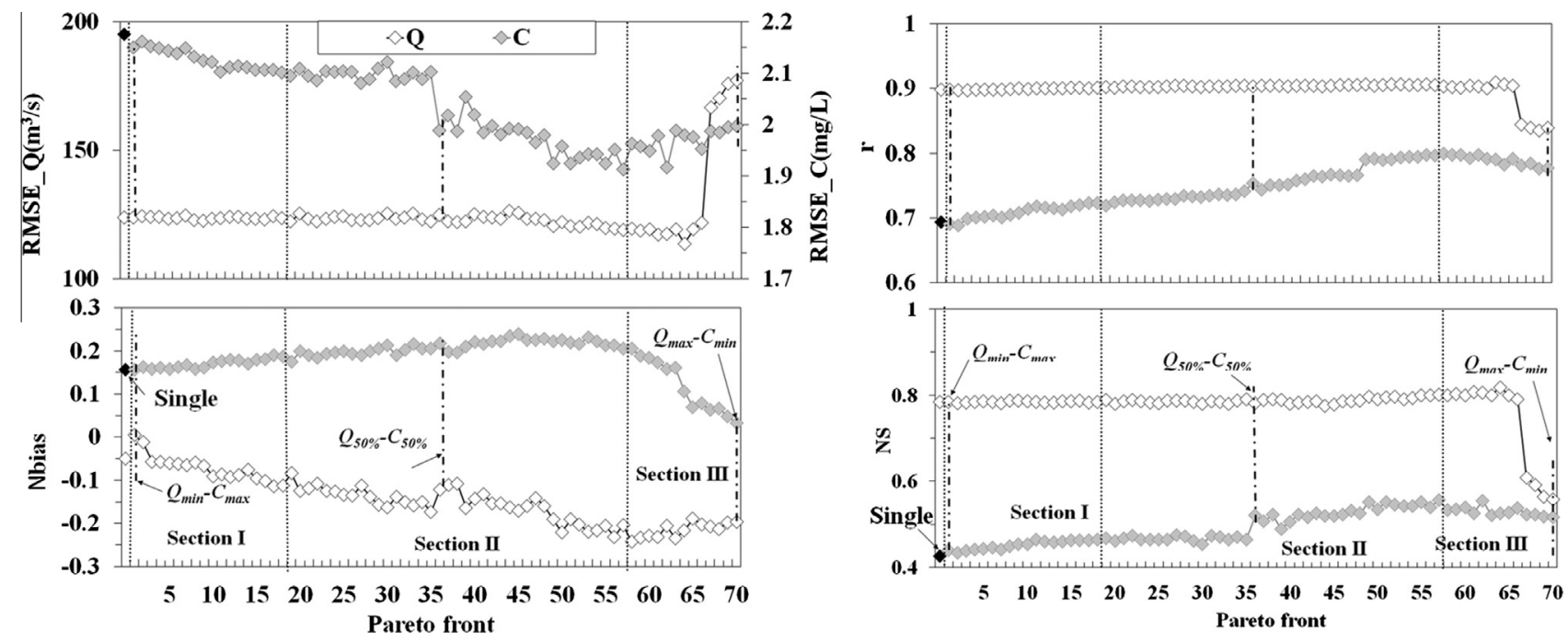

Fig. 8. The variation of all the evaluation criteria (RMSE, Nbias, $r$ and NS) along the Pareto front during the validation period.

$\mathrm{NH}_{4}-\mathrm{N}$ simulation were in the satisfactory rating while the runoff simulation varied from the satisfactory to very good ratings. Here the NS values changed most remarkably, i.e., from 0.558 (satisfactory) to 0.818 (very good).

Fig. 9 illustrated the comparison between the observations and simulations of runoff and $\mathrm{NH}_{4}-\mathrm{N}$ concentrations with extreme objective function values in the Pareto front. For the parameter set of $Q_{\min }-C_{\max }$, the runoff simulation was in the satisfactory rating, i.e., 0.157 for Nbias (satisfactory), 0.898 for $r$ (very good) and 0.784 for $N S$ (very good), respectively. But the RMSE_C $\left(2.15 \mathrm{~m}^{3} / \mathrm{s}\right)$ was very close to the maximum value $\left(2.162 \mathrm{~m}^{3} / \mathrm{s}\right)$ and the concentrations were also underestimated before the flood season (January to April), but overestimated in and after the flood season. The simulation performance of the $\mathrm{NH}_{4}-\mathrm{N}$ concentrations was in the unsatisfactory rating. For the parameter set of $Q_{\max }-C_{\min }$, the performance of runoff simulation was also the worst, particularly for the NS (0.558). However, the simulation of $\mathrm{NH}_{4}-\mathrm{N}$ concentrations was obviously improved and the performance was in the satisfactory rating, i.e., -0.197 for Nbias (good), 0.777 for $r$ (satisfactory) and 0.516 for NS (satisfactory), respectively. Only the simulated values obviously increased in the non-flood season of year 2007, but they still mismatched with observations remarkably. The trade-off between runoff and $\mathrm{NH}_{4}-\mathrm{N}$ simulations was also clear in the validation period.

\subsection{Parameter sets of Pareto front}

Fig. 10 gave the variations of normalized hydrological and water quality parameter values along the Pareto front. Over $70 \%$ of the normalized parameters showed no significant variations with 

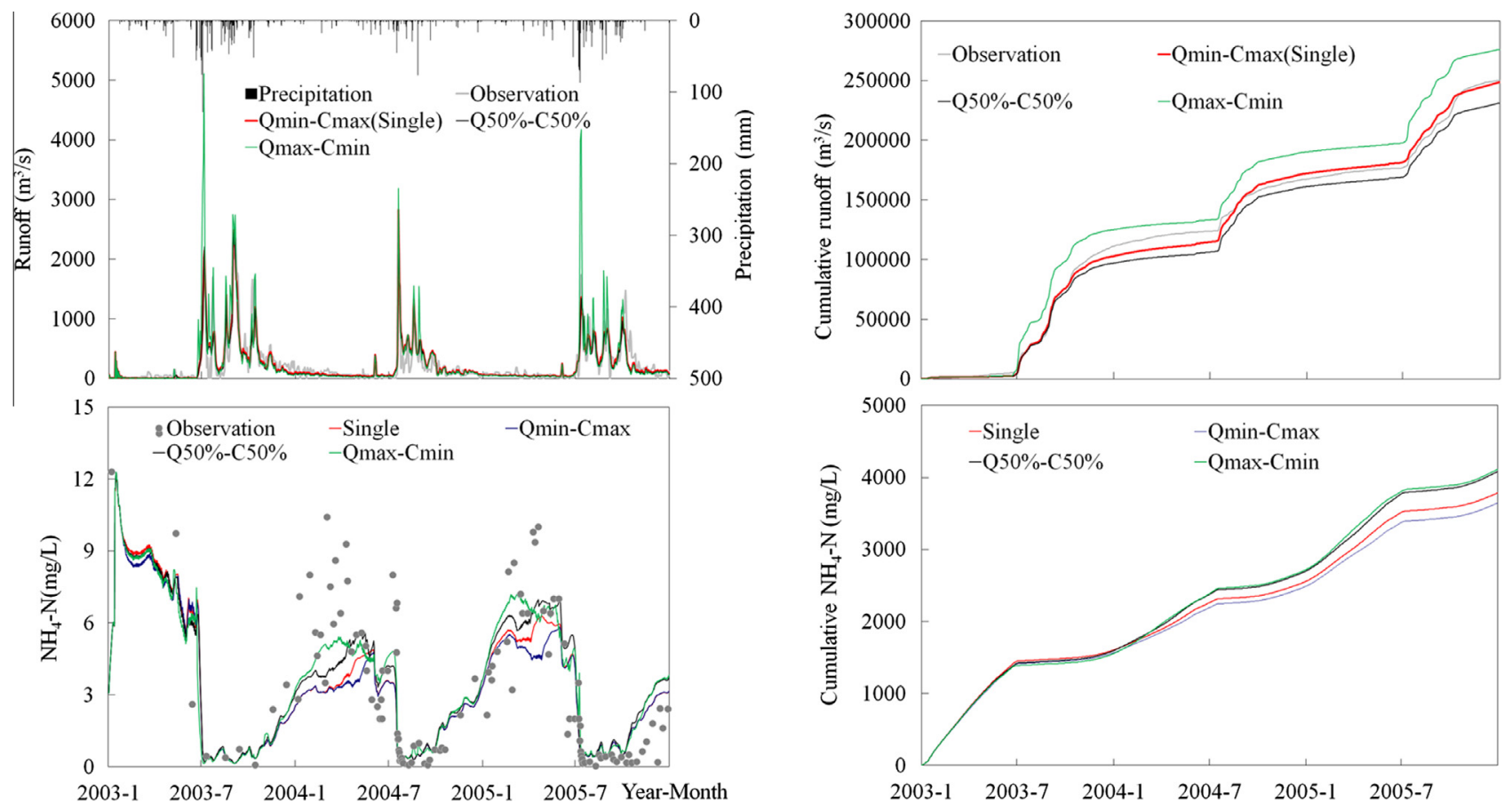

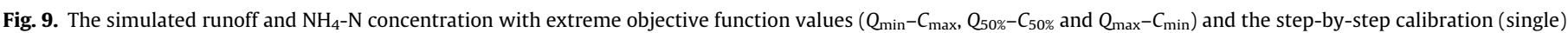
during the validation period.

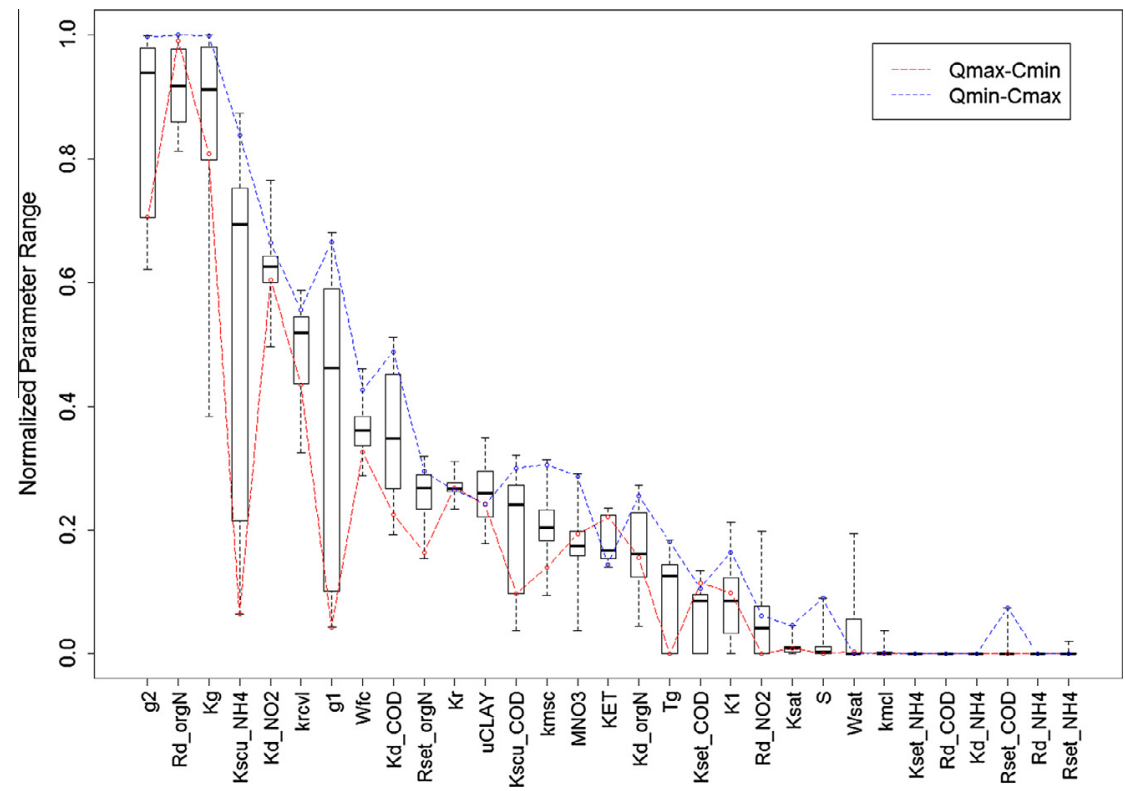

Fig. 10. Normalized hydrological and environmental parameter sets along Pareto front.

ranges of less than 0.25 . However, there were still three parameters $\left(g_{1}, K_{g}\right.$ and $\left.K_{\text {scu }}\left(\mathrm{NH}_{4}\right)\right)$ having variation ranges of over 0.50 due to their trade-offs between the runoff and $\mathrm{NH}_{4}-\mathrm{N}$ objectives, i.e., these parameters had positive correlations with the runoff simulation performance, but negative correlations with the $\mathrm{NH}_{4}-\mathrm{N}$ simulation performance.

The correlations between each pair within the full suite of 31 parameters (435 pairs) were tested by Pearson's correlation coefficient and $t$-tests. Although nearly half of total pairs had significant correlations at a 95\% confidence level, the correlations were quite low and only $3.21 \%$ of pairs had strong correlations (i.e. $r \geqslant 0.75$ )
(Table 3). Thus, most parameters of HEQM were well defined and could be calibrated using the multi-objective optimization algorithm. The hydrological parameters $\left(g_{1}, g_{2}, T_{g}\right.$ and $\left.K_{\text {sat }}\right)$ were negatively correlated with $R M S E_{-} Q$, but obviously positively correlated with RMSE_C except $T_{g}$ and $K_{\text {sat }}$. The correlations of $K_{E T}$ with $R M S E_{-} Q$ and $R M S E_{-} C$ were just the opposite. Moreover, water quality parameters $\left(R_{\text {set }}(\mathrm{COD}), K_{d}(\mathrm{COD}), K_{d}\left(\mathrm{NH}_{4}\right)\right.$ and $\left.K_{\text {scu }}\left(\mathrm{NH}_{4}\right)\right)$ had positive correlations with $R M S E_{-} C$, but only the correlation coefficients of $K_{d}(\mathrm{COD})$ and $K_{\text {scu }}(\mathrm{COD})$ were greater than 0.75 . Thus, in order to improve the simulation performances of runoff and $\mathrm{NH}_{4}-\mathrm{N}$ concentrations, the variations of hydrological $\left(g_{1}, g_{2}\right.$ and 
Table 3

The highly correlated parameter pairs and their correlation coefficients.

\begin{tabular}{|c|c|c|c|c|c|c|c|c|c|}
\hline Parameters & $g_{2}$ & $K_{E T}$ & $T_{g}$ & $R_{\text {set }}(\mathrm{COD})$ & $K_{d}(\mathrm{COD})$ & $K_{d}\left(\mathrm{NH}_{4}\right)$ & $K_{\text {scu }}(\mathrm{COD})$ & RSEM_Q & RSEM_C \\
\hline$g_{1}$ & 0.82 & -0.88 & 0.89 & & 0.92 & & 0.85 & NR & 0.88 \\
\hline$g_{2}$ & & -0.92 & 0.94 & & & & 0.82 & NR & 0.76 \\
\hline$K_{E T}$ & & & -0.94 & & & & -0.79 & PR & -0.83 \\
\hline$T_{g}$ & & & & & 0.76 & & 0.84 & NR & \\
\hline$K_{\text {sat }}$ & & & & 0.76 & & & & NR & \\
\hline$R_{\text {set }}(\mathrm{COD})$ & & & & & & 0.92 & & & PR \\
\hline$K_{d}(\mathrm{COD})$ & & & & & & & & & 0.76 \\
\hline$K_{d}\left(\mathrm{NH}_{4}\right)$ & & & & & & & & & PR \\
\hline$K_{\text {scu }}(\mathrm{COD})$ & & & & & & & & & 0.75 \\
\hline
\end{tabular}

Note: "NR" means negative correlation whose coefficient is between -0.75 and 0.00 ; "PR" means positive correlation whose coefficient is between 0.0 and 0.75 .

$\left.T_{g}\right)$ and water quality parameters $\left(R_{\text {set }}(\mathrm{COD}), K_{d}(\mathrm{COD}), K_{d}\left(\mathrm{NH}_{4}\right)\right.$ and $K_{\text {scu }}(\mathrm{COD})$ ) were consistent, which were just opposite with the variation of $K_{E T}$.

\subsection{Comparison with traditional step-by-step procedure}

The objective function values of Pareto optimal solutions were also compared with the results of the traditional step-by-step procedure. In the calibration period, the function values of the stepby-step procedure were located in the middle of the dominated section for $\mathrm{NH}_{4}-\mathrm{N}$ improvement, and tended to the objective function value of $\left(Q_{\min }-C_{\max }\right)$ solution (Figs. 5a and 6$)$. Although the runoff calibration reached the optima (Nbias $=0.007, r=0.901$ and $N S=0.812$ ), there was still a potential to improve $\mathrm{NH}_{4}-\mathrm{N}$ simulation (Table A1). The RMSE_C was $2.574 \mathrm{mg} / \mathrm{L}$, which was $9.1 \%$ greater than the optimal value $(2.359 \mathrm{mg} / \mathrm{L})$. Particularly in the dominated section for $\mathrm{NH}_{4}-\mathrm{N}$ improvement, the ECQ was 7.22 and RMSE_C decreased by $2.60 \%$ from 2.574 to $2.507 \mathrm{mg} / \mathrm{L}$ by a slight increase of RMSE_Q (0.36\% from 159.460 to $\left.160.041 \mathrm{~m}^{3} / \mathrm{s}\right)$. The values of Nbias, $r$ and $\mathrm{NS}$ of $\mathrm{NH}_{4}-\mathrm{N}$ simulation would also be improved. Although the $r$ values changed very slightly, the Nbias decreased most obviously, from 0.216 (good) to 0.150 (very good) while the NS values increased from 0.553 (satisfactory) to 0.576 (satisfactory). However, the model performance of runoff was still at the very good rating.

In the validation period, the function values of the step-by-step procedure were also located in the dominated section for $\mathrm{NH}_{4}-\mathrm{N}$ improvement (Fig. 8). The runoff simulation criteria of the stepby-step procedure were the same as those of the $\left(Q_{\min }-C_{\max }\right)$ solution (RMSE_Q $=123.722 \mathrm{~m}^{3} / \mathrm{s}, \quad$ Nbias $=0.157, \quad r=0.898$ and $N S=0.784$, i.e., the satisfactory rating), but the $\mathrm{NH}_{4}$-N performance was even worse. The RMSE_C and $r$ values increased from 2.150 to $2.176 \mathrm{mg} / \mathrm{L}$ and 0.691 to 0.694 , but the Nbias $r$ and NS values decreased from 0.005 to -0.050 and from 0.440 to 0.426 , respectively. Thus, the traditional step-by-step procedure did not reach the reasonable optima of all the objectives of HEQM in the validation period either.

Furthermore, it was proved that the traditional step-by-step procedure just achieved the local optima of the first objective. It was more difficult to get the optima if the calibration was at the higher stage. On the one hand, the errors of pre-calibrated processes were gradually accumulated to the post-calibrated processes; On the other hand, the observation sources were only used to calibrate their dominated processes, and the underlying information of other related processes was always ignored. Thus, it was impossible to get the holistic optima of all the processes for the water system model using the step-by-step calibration procedure. Generally, the existing models usually had a dominated process to connect all of these subsystems, such as hydrological process of SWAT and HEQM, biochemical process of DNDC (Li et al., 1992; Deng et al., 2011). Nevertheless, along with the absorption of multiple data sources from different processes, it was no longer suitable to calibrate the dominated processes and other processes sequentially. Moreover, the concerned objectives might be significantly improved at the slight expense of the dominated process or other processes simulation. Simultaneous multiprocess calibration by Pareto- optimization was an effective and scientific approach to achieve the holistic optima of the water system model, and to take full advantage of all the useful observation sources instead of the traditional step-by-step procedure.

\section{Conclusions}

The global optimization of an integrated water system model is difficult due to the complicate interactions among the waterrelated processes and the integration of multi-source observations. The traditional step-by-step calibration approach was usually unable to achieve reasonable solutions for all objectives, especially for the high-order objectives (last few objectives) in the multistage calibration. In this study, a combined auto-calibration of water quantity and quality for the integrated water system model (HEQM) was presented using a multi-objective evolutionary algorithm (NSGA-II). Moreover, the rationality and feasibility of this approach was tested by parameter analysis and comparison with the results of traditional step-by-step calibration. The results of our study demonstrated that:

(1) Hydrological and water quality processes were symbiotic and closely interactive. Although the hydrological cycle was one of the driving factors for the migration and degradation of water quality variables, several water quality processes also acted on the hydrological cycle. For example, the loss of nutrient substance along with water routing, would restrict plant growth due to nitrogen stress and indirectly affect the plant transpiration process. Moreover, water quality observations could help constrain the hydrological processes. Water quality concentration observations could act as a reference to calibrate low flow regimes.

(2) Pareto optimal solutions were formed between RMSE of simulated runoff and $\mathrm{NH}_{4}-\mathrm{N}$ concentration by NSGA-II at our study station. The integrated water system model could capture runoff and $\mathrm{NH}_{4}-\mathrm{N}$ concentration reasonably in both calibration and validation periods. Along the Pareto optimal solutions, the runoff simulation varied from the very good rating to unsatisfactory rating, while the $\mathrm{NH}_{4}-\mathrm{N}$ simulation varied from the unsatisfactory rating to good rating in the calibration period. In the validation period, the runoff simulation also varied from the good rating to satisfactory rating, while the $\mathrm{NH}_{4}-\mathrm{N}$ simulation varied from the unsatisfactory rating to satisfactory rating. Thus, the simulation performances of runoff and water quality were highly mutually affected and the trade-off was clear in both the calibration and validation periods. The slight reduction in runoff simulation accuracy significantly improved the simulation 
Table A1

The list of all criteria results along Pareto front in the calibration ad validation periods.

\begin{tabular}{|c|c|c|c|c|c|c|c|c|c|c|c|c|c|c|c|c|c|c|c|}
\hline \multirow[t]{3}{*}{ ID } & & \multirow[t]{3}{*}{ Dominated area } & \multirow[t]{3}{*}{ ECQ } & \multicolumn{8}{|c|}{ Calibration (2003-2005) } & \multicolumn{8}{|c|}{ Validation (2006-2007) } \\
\hline & & & & \multicolumn{4}{|c|}{ Runoff } & \multicolumn{4}{|l|}{$\mathrm{NH}_{4}-\mathrm{N}$} & \multicolumn{4}{|c|}{ Runoff } & \multicolumn{4}{|l|}{$\mathrm{NH}_{4}-\mathrm{N}$} \\
\hline & & & & $R M S E_{-} Q$ & Nbias & $r$ & NS & $R M S E_{-} C$ & Nbias & $r$ & NS & $R M S E_{-} Q$ & Nbias & $r$ & NS & $R M S E_{-} C$ & Nbias & $r$ & NS \\
\hline \multicolumn{2}{|l|}{ Single-objective } & & - & 159.460 & 0.007 & 0.901 & 0.812 & 2.574 & 0.216 & 0.804 & 0.553 & 123.722 & 0.157 & 0.898 & 0.784 & 2.176 & -0.050 & 0.694 & 0.426 \\
\hline Multi-objective & 1 & Dominated section for $\mathrm{NH}_{4}-\mathrm{N}$ & - & 159.460 & 0.007 & 0.901 & 0.812 & 2.713 & 0.249 & 0.786 & 0.503 & 123.722 & 0.157 & 0.898 & 0.784 & 2.150 & 0.005 & 0.691 & 0.440 \\
\hline & 2 & improvement & -352.91 & 159.464 & 0.012 & 0.901 & 0.812 & 2.686 & 0.240 & 0.787 & 0.513 & 124.457 & 0.163 & 0.897 & 0.782 & 2.162 & -0.012 & 0.689 & 0.434 \\
\hline & 3 & & -144.49 & 159.508 & 0.011 & 0.901 & 0.811 & 2.579 & 0.203 & 0.796 & 0.551 & 124.099 & 0.159 & 0.897 & 0.783 & 2.153 & -0.057 & 0.699 & 0.438 \\
\hline & 4 & & -8.88 & 159.550 & 0.013 & 0.901 & 0.811 & 2.573 & 0.197 & 0.794 & 0.553 & 123.959 & 0.161 & 0.898 & 0.784 & 2.149 & -0.058 & 0.701 & 0.441 \\
\hline & 5 & & -5.95 & 159.608 & 0.013 & 0.901 & 0.811 & 2.567 & 0.194 & 0.794 & 0.555 & 123.315 & 0.159 & 0.898 & 0.786 & 2.144 & -0.060 & 0.702 & 0.443 \\
\hline & 6 & & -22.58 & 159.622 & 0.017 & 0.901 & 0.811 & 2.562 & 0.194 & 0.796 & 0.557 & 123.564 & 0.163 & 0.898 & 0.785 & 2.138 & -0.062 & 0.704 & 0.446 \\
\hline & 7 & & -21.30 & 159.630 & 0.021 & 0.901 & 0.811 & 2.560 & 0.190 & 0.794 & 0.558 & 124.646 & 0.167 & 0.898 & 0.781 & 2.149 & -0.065 & 0.701 & 0.441 \\
\hline & 8 & & -15.13 & 159.665 & 0.014 & 0.901 & 0.811 & 2.551 & 0.184 & 0.794 & 0.561 & 122.682 & 0.159 & 0.899 & 0.788 & 2.132 & -0.059 & 0.705 & 0.449 \\
\hline & 9 & & -11.43 & 159.677 & 0.015 & 0.902 & 0.811 & 2.549 & 0.183 & 0.794 & 0.561 & 122.589 & 0.162 & 0.900 & 0.788 & 2.124 & -0.066 & 0.708 & 0.453 \\
\hline & 10 & & -10.19 & 159.699 & 0.024 & 0.901 & 0.811 & 2.545 & 0.176 & 0.792 & 0.563 & 123.395 & 0.173 & 0.899 & 0.786 & 2.122 & -0.091 & 0.714 & 0.454 \\
\hline & 11 & & -53.94 & 159.714 & 0.026 & 0.901 & 0.811 & 2.532 & 0.172 & 0.793 & 0.567 & 123.557 & 0.177 & 0.900 & 0.785 & 2.103 & -0.086 & 0.718 & 0.464 \\
\hline & 12 & & -0.50 & 159.811 & 0.031 & 0.901 & 0.811 & 2.532 & 0.170 & 0.793 & 0.567 & 124.079 & 0.180 & 0.900 & 0.783 & 2.112 & -0.093 & 0.716 & 0.460 \\
\hline & 13 & & -1.91 & 159.861 & 0.034 & 0.901 & 0.811 & 2.530 & 0.167 & 0.792 & 0.568 & 124.030 & 0.178 & 0.900 & 0.783 & 2.114 & -0.088 & 0.715 & 0.459 \\
\hline & 14 & & -0.39 & 159.921 & 0.033 & 0.901 & 0.810 & 2.530 & 0.168 & 0.793 & 0.568 & 123.305 & 0.170 & 0.900 & 0.786 & 2.112 & -0.075 & 0.713 & 0.460 \\
\hline & 15 & & -23.14 & 159.941 & 0.034 & 0.901 & 0.810 & 2.522 & 0.156 & 0.790 & 0.571 & 123.221 & 0.180 & 0.901 & 0.786 & 2.106 & -0.096 & 0.718 & 0.463 \\
\hline & 16 & & -51.53 & 159.947 & 0.034 & 0.901 & 0.810 & 2.517 & 0.159 & 0.793 & 0.572 & 122.989 & 0.181 & 0.901 & 0.787 & 2.106 & -0.102 & 0.720 & 0.463 \\
\hline & 17 & & -3.31 & 160.010 & 0.042 & 0.901 & 0.810 & 2.514 & 0.160 & 0.795 & 0.573 & 124.287 & 0.190 & 0.900 & 0.783 & 2.106 & -0.114 & 0.723 & 0.463 \\
\hline & 18 & & -13.72 & 160.041 & 0.040 & 0.901 & 0.810 & 2.507 & 0.150 & 0.795 & 0.576 & 123.599 & 0.187 & 0.901 & 0.785 & 2.101 & -0.112 & 0.723 & 0.465 \\
\hline & 19 & Trade-off section between & -0.69 & 160.249 & 0.032 & 0.901 & 0.810 & 2.505 & 0.151 & 0.794 & 0.576 & 122.287 & 0.175 & 0.902 & 0.789 & 2.095 & -0.084 & 0.719 & 0.468 \\
\hline & 20 & $\mathrm{NH}_{4}-\mathrm{N}$ and $\mathrm{Q}$ & -0.75 & 160.413 & 0.053 & 0.900 & 0.809 & 2.503 & 0.147 & 0.792 & 0.577 & 125.344 & 0.199 & 0.901 & 0.779 & 2.109 & -0.125 & 0.724 & 0.461 \\
\hline & 21 & & -1.08 & 160.426 & 0.044 & 0.900 & 0.809 & 2.503 & 0.151 & 0.795 & 0.577 & 123.292 & 0.190 & 0.903 & 0.786 & 2.095 & -0.118 & 0.727 & 0.468 \\
\hline & 22 & & -4.32 & 160.449 & 0.052 & 0.900 & 0.809 & 2.501 & 0.140 & 0.791 & 0.578 & 122.407 & 0.185 & 0.903 & 0.789 & 2.086 & -0.108 & 0.727 & 0.473 \\
\hline & 23 & & -2.12 & 160.510 & 0.041 & 0.900 & 0.809 & 2.499 & 0.142 & 0.792 & 0.578 & 123.368 & 0.193 & 0.902 & 0.786 & 2.104 & -0.125 & 0.727 & 0.464 \\
\hline & 24 & & -0.50 & 160.513 & 0.048 & 0.900 & 0.809 & 2.499 & 0.139 & 0.791 & 0.578 & 124.191 & 0.197 & 0.902 & 0.783 & 2.103 & -0.126 & 0.726 & 0.464 \\
\hline & 25 & & -1.64 & 160.591 & 0.054 & 0.900 & 0.809 & 2.497 & 0.139 & 0.792 & 0.579 & 124.398 & 0.200 & 0.902 & 0.782 & 2.104 & -0.134 & 0.728 & 0.464 \\
\hline & 26 & & -0.17 & 160.815 & 0.046 & 0.900 & 0.808 & 2.497 & 0.144 & 0.793 & 0.579 & 122.871 & 0.193 & 0.903 & 0.787 & 2.103 & -0.136 & 0.729 & 0.464 \\
\hline & 27 & & -1.72 & 160.871 & 0.048 & 0.900 & 0.808 & 2.495 & 0.129 & 0.789 & 0.580 & 122.842 & 0.190 & 0.904 & 0.788 & 2.081 & -0.112 & 0.729 & 0.475 \\
\hline & 28 & & -0.27 & 160.907 & 0.055 & 0.900 & 0.808 & 2.495 & 0.127 & 0.788 & 0.580 & 122.708 & 0.199 & 0.904 & 0.788 & 2.088 & -0.138 & 0.735 & 0.472 \\
\hline & 29 & & -23.79 & 160.912 & 0.058 & 0.900 & 0.808 & 2.493 & 0.123 & 0.787 & 0.581 & 123.647 & 0.205 & 0.903 & 0.785 & 2.109 & -0.157 & 0.734 & 0.461 \\
\hline & 30 & & -0.06 & 161.009 & 0.065 & 0.900 & 0.808 & 2.493 & 0.127 & 0.788 & 0.581 & 125.291 & 0.213 & 0.902 & 0.779 & 2.122 & -0.163 & 0.732 & 0.454 \\
\hline & 31 & & -1.39 & 161.051 & 0.053 & 0.900 & 0.808 & 2.492 & 0.132 & 0.791 & 0.581 & 123.292 & 0.190 & 0.903 & 0.786 & 2.084 & -0.138 & 0.735 & 0.474 \\
\hline & 32 & & -4.77 & 161.093 & 0.056 & 0.900 & 0.808 & 2.489 & 0.133 & 0.792 & 0.582 & 123.704 & 0.202 & 0.903 & 0.785 & 2.089 & -0.150 & 0.737 & 0.471 \\
\hline & 33 & & -1.22 & 161.359 & 0.070 & 0.899 & 0.807 & 2.484 & 0.120 & 0.789 & 0.584 & 125.373 & 0.216 & 0.903 & 0.779 & 2.101 & -0.159 & 0.736 & 0.465 \\
\hline & 34 & & -0.80 & 161.483 & 0.062 & 0.899 & 0.807 & 2.482 & 0.120 & 0.789 & 0.584 & 122.970 & 0.205 & 0.904 & 0.787 & 2.089 & -0.150 & 0.737 & 0.471 \\
\hline & 35 & & -1.19 & 161.604 & 0.057 & 0.900 & 0.806 & 2.480 & 0.113 & 0.788 & 0.585 & 122.217 & 0.206 & 0.904 & 0.790 & 2.103 & -0.174 & 0.742 & 0.464 \\
\hline & 36 & & -0.89 & 161.956 & 0.077 & 0.899 & 0.806 & 2.475 & 0.121 & 0.793 & 0.586 & 124.773 & 0.218 & 0.903 & 0.781 & 1.989 & -0.122 & 0.754 & 0.521 \\
\hline & 37 & & -0.03 & 162.258 & 0.059 & 0.898 & 0.805 & 2.475 & 0.135 & 0.797 & 0.587 & 122.352 & 0.198 & 0.904 & 0.789 & 2.018 & -0.111 & 0.744 & 0.507 \\
\hline & 38 & & -5.82 & 162.278 & 0.055 & 0.899 & 0.805 & 2.473 & 0.126 & 0.795 & 0.587 & 121.942 & 0.196 & 0.904 & 0.791 & 1.987 & -0.108 & 0.751 & 0.522 \\
\hline & 39 & & -1.48 & 162.368 & 0.065 & 0.899 & 0.805 & 2.471 & 0.104 & 0.787 & 0.588 & 122.345 & 0.210 & 0.904 & 0.789 & 2.054 & -0.164 & 0.751 & 0.489 \\
\hline & 40 & & -1.11 & 162.650 & 0.076 & 0.898 & 0.804 & 2.466 & 0.125 & 0.796 & 0.589 & 125.172 & 0.221 & 0.903 & 0.779 & 2.019 & -0.143 & 0.752 & 0.506 \\
\hline & 41 & & -1.26 & 162.879 & 0.076 & 0.898 & 0.803 & 2.462 & 0.116 & 0.794 & 0.591 & 124.157 & 0.217 & 0.904 & 0.783 & 1.984 & -0.133 & 0.758 & 0.523 \\
\hline & 42 & & -13.60 & 162.914 & 0.078 & 0.898 & 0.803 & 2.455 & 0.115 & 0.796 & 0.593 & 123.806 & 0.223 & 0.904 & 0.784 & 1.998 & -0.153 & 0.760 & 0.517 \\
\hline & 43 & & -0.55 & 163.318 & 0.080 & 0.898 & 0.802 & 2.451 & 0.110 & 0.796 & 0.594 & 123.285 & 0.222 & 0.904 & 0.786 & 1.981 & -0.154 & 0.765 & 0.525 \\
\hline & 44 & & -0.94 & 163.653 & 0.096 & 0.897 & 0.802 & 2.447 & 0.101 & 0.794 & 0.596 & 126.502 & 0.235 & 0.903 & 0.775 & 1.992 & -0.163 & 0.764 & 0.519 \\
\hline & 45 & & -3.49 & 163.689 & 0.097 & 0.897 & 0.801 & 2.445 & 0.107 & 0.797 & 0.597 & 125.522 & 0.239 & 0.904 & 0.778 & 1.991 & -0.171 & 0.767 & 0.520 \\
\hline & 46 & & -0.95 & 163.722 & 0.084 & 0.897 & 0.801 & 2.444 & 0.107 & 0.797 & 0.597 & 123.240 & 0.226 & 0.905 & 0.786 & 1.984 & -0.160 & 0.766 & 0.523 \\
\hline & 47 & & -0.02 & 163.982 & 0.094 & 0.897 & 0.801 & 2.444 & 0.125 & 0.804 & 0.597 & 123.408 & 0.226 & 0.905 & 0.786 & 1.965 & -0.141 & 0.765 & 0.532 \\
\hline & 48 & & -1.37 & 164.157 & 0.095 & 0.897 & 0.800 & 2.441 & 0.118 & 0.803 & 0.598 & 122.928 & 0.228 & 0.905 & 0.787 & 1.98 & -0.160 & 0.766 & 0.525 \\
\hline & 49 & & -5.16 & 164.353 & 0.095 & 0.897 & 0.800 & 2.426 & 0.069 & 0.791 & 0.603 & 120.458 & 0.222 & 0.906 & 0.796 & 1.924 & -0.191 & 0.790 & 0.552 \\
\hline & 50 & & -1.21 & 164.525 & 0.098 & 0.897 & 0.799 & 2.423 & 0.040 & 0.785 & 0.604 & 122.076 & 0.225 & 0.904 & 0.790 & 1.958 & -0.221 & 0.792 & 0.535 \\
\hline
\end{tabular}

(continued on next page) 


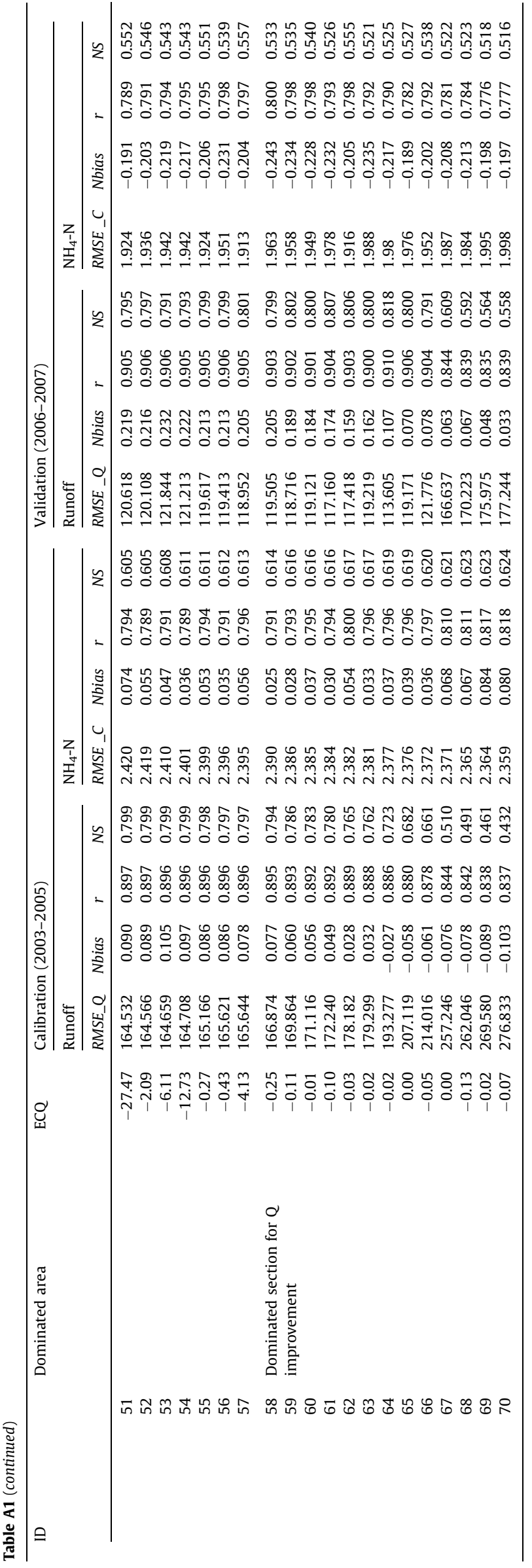

performance of $\mathrm{NH}_{4}-\mathrm{N}$ concentration. Managers and other stake-holders could choose a satisfying solution according to specific objectives.

(3) The traditional step-by-step procedure just achieved the local optimum of runoff simulation, and there was a great potential to improve the $\mathrm{NH}_{4}-\mathrm{N}$ simulation with the slight sacrifice of runoff simulation performance. This procedure was not able to deliver the reasonable solutions for all of the considered processes in the integrated water system model, due to the high level of interactions of the multiprocess, the underutilization of the multi-source observations and error accumulations.

In our study, only the parameter uncertainty about the runoff and water quality simulations was investigated. Besides this uncertainty source, the simulation performances were also affected by the uncertainties of data input, model structure and calibration observations because of the complicated model structure and numerous indispensable input data sets (Yang et al., 2008; Li et al., 2010a; Zhang et al., 2016). More attentions should be paid to addressing the effects of all uncertainty sources. Advanced analysis technologies would benefit the future model improvement and parameter optimization, such as Bayesian method (Yang et al., 2007; Li et al., 2010c; Yen et al., 2014), autoregressive error models (Duan et al., 1988; Yang et al., 2008), data assimilation (Vrugt et al., 2005), and sequential data assimilation (Moradkhani et al., 2005).

\section{Acknowledgements}

This study was supported by the Natural Science Foundation of China (No. 41271005), the China Youth Innovation Promotion Association CAS (No. 2014041), the Program for "Bingwei" Excellent Talents in IGSNRR CAS (No. 2015RC201), the Endeavour Research Fellowship, CSIRO Computational and Simulation Sciences Transformational Capability Platform (CSS TCP) and China Visiting Scholar Project. Thanks to Dr Tony Zhao for his helpful comments during our internal review.

\section{Appendix A.}

See Table A1.

\section{References}

Abido, M.A., 2006. Multiobjective evolutionary algorithms for electric power dispatch problem. IEEE Trans. Evolut. Comput. 10 (3), 315-329.

Afshar, A., Hamideh, K., 2012. Multi objective calibration of large scaled water quality model using a hybrid particle swarm optimization and neural network algorithm. KSCE J. Civ. Eng. 16 (6), 913-918.

Ahmadi, M., Arabi, M., James, I.I., Fontane, D.G., Engel, B.A., 2014. Toward improved calibration of watershed models: multisite multiobjective measures of information. Environ. Modell. Softw. 59, 135-145.

Arnold, J.G., Srinivasan, R., Muttiah, R.S., Williams, J.R., 1998. Large-area hydrologic modeling and assessment: Part I. Model development. J. Am. Water Resour. Assoc. 34, 73-89.

Aubert, A.H., Tavenard, R., Emonet, R., Lavenne, A., Malinowski, S., Guyet, T. Quiniou, R., M.Odobez, J., Merpt, P., Gascuel-Odoux, C., 2013. Clustering flood events from water quality time series using Latent Dirichlet Allocation model. Water Resour. Res. 49 (12), 8187-8199.

Bekele, E.G., Nicklow, J.W., 2007. Multi-objective automatic calibration of SWAT using NSGA-II. J. Hydrol. 341 (3), 165-176.

Boyle, D.P., Gupta, H.V., Sorooshian, S., 2000. Toward improved calibration of hydrologic models: combining the strengths of manual and automatic methods. Water Resour. Res. 36 (12), 3663-3674.

Cheng, C.T., Ou, C.P. Chau, K.W., 2002. Combining a fuzzy optima model with a genetic algorithm to solve multi-objective rainfall-runoff model calibration. J. Hydrol. 268 (1), 72-86.

Coello, C.C.A., 2006. Evolutionary multi-objective optimization: a historical view of the field. IEEE Comput. Intell. Mag. 1 (1), 28-36.

Deb, K., Goel, T., 2001. A hybrid multi-objective evolutionary approach to engineering shape design. Lect. Notes Comput. Sci. 1993, 385-399. 
Deb, K., Pratap, A., Agarwal, S., Meyarivan, T., 2002. A fast and elitist multiobjective genetic algorithm: NSGA-II. IEEE Trans. Evolut. Comput. 6 (2), 182-197.

Deng, J., Zhu, B., Zhou, Z., Zheng, X.H., Li, C.S., Wang, T., Tang, J.L., 2011. Modeling nitrogen loadings from agricultural soils in southwest China with modified DNDC. J. Geophys. Res. 116 (G2) (2005-2012).

Duan, Q.Y., Sorooshian, S., Ibbitt, R.P., 1988. A maximum likelihood criterion for use with data collected at unequal time intervals. Water Resour. Res. 24 (7), 11631173.

Duan, Q., Sorooshian, S., Gupta, V., 1992. Effective and efficient global optimization for conceptual rainfall-runoff models. Water Resour. Res. 28 (4), 1015-1031.

Efstratiadis, A., Koutsoyiannis, D., 2010. One decade of multi-objective calibration approaches in hydrological modelling: a review. Hydrol. Sci. J. 55 (1), 58-78.

Engel, B., Storm, D., White, M., Arnold, J., Arabi, M., 2007. A hydrologic/water quality model application protocol. J. Am. Water Resour. Assoc. 45 (5), 1223-1236.

Fenicia, F., Savenije, H.H.G., Matgen, P., Pfister, L., 2007. A comparison of alternative multiobjective calibration strategies for hydrological modeling. Water Resour. Res. 43 (3).

Francos, A., Bidoglio, G., Galbiati, L., Bouraoui, F., Elorza, F.J., Rekolainen, S., Manni, K., Granlund, K., 2001. Hydrological and water quality modelling in a mediumsized coastal basin. Phys. Chem. Earth 26 (1), 47-52.

Gupta, H.V., Sorooshian, S., Yapo, P.O., 1998. Toward improved calibration of hydrologic models: multiple and noncommensurable measures of information. Water Resour. Res. 34 (4), 751-763.

Gupta, H.V., Sorooshian, S., Yapo, P.O., 1999. Status of automatic calibration for hydrologic models: comparison with multilevel expert calibration. J. Hydrol Eng. 4 (2), 135-143.

Hesse, C., Krysanova, V., Päzolt, J., Hattermann, F.F., 2008. Eco-hydrological modelling in a highly regulated lowland catchment to find measures for improving water quality. Ecol. Model. 218, 135-148.

Huang, Y., 2014. Multi-objective calibration of a reservoir water quality model in aggregation and non-dominated sorting approaches. J. Hydrol. 510, 280292.

Kang, M.S., W Park, S., Lee, J.J., Yoo, K.H., 2006. Applying SWAT for TMDL programs to a small watershed containing rice paddy fields. Agric. Water Manage. 79 (1), $72-92$.

Khu, S.T., Madsen, H., 2005. Multiobjective calibration with Pareto preference ordering: an application to rainfall-runoff model calibration. Water Resour. Res. 41 (3).

Kirchner, J.W., 2006. Getting the right answers for the right reasons: linking measurements, analyses, and models to advance the science of hydrology. Water Resour. Res. 42 (3).

Kollat, J.B., Reed, P.M., 2006. Comparing state-of-the-art evolutionary multiobjective algorithms for long-term groundwater monitoring design. Adv. Water Resour. 29 (6), 792-807.

Krauße, T., Cullmann, J., Saile, P., Schmitz, G.H., 2012. Robust multi-objective calibration strategies-possibilities for improving flood forecasting. Hydrol. Earth Syst. Sci. 16 (10)

Li, C., Frolking, S., Frolking, T.A., 1992. A model of nitrous oxide evolution from soil driven by rainfall events: 1. Model structure and sensitivity. J. Geophys. Res. 97 (D9), 9759-9776 (1984-2012).

Li, L., Xia, J., Xu, C.-Y., Singh, V.P., 2010a. Evaluation of the subjective factors of the GLUE method and comparison with the formal Bayesian method in uncertainty assessment of hydrological models. J. Hydrol. 390 (3-4), 210-221.

Li, X., Weller, D.E., Jordan, T.E., 2010b. Watershed model calibration using multiobjective optimization and multi-site averaging. J. Hydrol. 380, 277-288.

Li, Z.L., Shao, Q.X., Xu, Z.X., Cai, X.T., 2010c. Analysis of parameter uncertainty in semi-distributed hydrological models using bootstrap method: a case study of SWAT model applied to Yingluoxia watershed in northwest China. J. Hydrol. 385, 76-83.

Liu, D.D., Guo, S.X., Chen, X.H., Shao, Q.X., Ran, Q.H., Song, X.Y., Wang, Z.L., 2012. A macro-evolutionary multi-objective immune algorithm with application to optimal allocation of water resources in Dongjiang River basins, South China. Stoch. Environ. Res. Risk A 26, 491-507.

Liu, D.D., Guo, S.X., Shao, Q.X., Jiang, Y.Z., Chen, X.H., 2014. Optimal allocation of water quantity and waste load in the Northwest Pearl River Delta, China. Stoch. Environ. Res. Risk A 28, 1525-1542.

Liong, S.Y., Khu, S.T., Chan, W.T., 2001. Derivation of Pareto front with genetic algorithm and neural network. J. Hydrol. Eng. 6 (1), 52-61.

Madsen, H., 2000. Automatic calibration of a conceptual rainfall-runoff model using multiple objectives. J. Hydrol. 235 (3), 276-288.

Madsen, H., 2003. Parameter estimation in distributed hydrological catchment modelling using automatic calibration with multiple objectives. Adv. Water Resour. 26 (2), 205-216.

Maringanti, C., Chaubey, I., Popp, J., 2009. Development of a multiobjective optimization tool for the selection and placement of best management practices for nonpoint source pollution control. Water Resour. Res. 45 (6).

McCown, R.L., Hammer, G.L., Hargreaves, J.N.G., Holzworth, D.P., Freebairn, D.M., 1996. APSIM: a novel software system for model development, model testing, and simulation in agricultural systems research. Agric. Syst. 50, 255-271.

Meixner, T., Bastidas, L.A., Gupta, H.V., Bales, R.C., 2002. Multicriteria parameter estimation for models of stream chemical composition. Water Resour. Res. 38 (3), 1027.

Moradkhani, H., Hsu, K.-L., Gupta, H., Sorooshian, S., 2005. Uncertainty assessment of hydrologic model states and parameters: sequential data assimilation using the particle filter. Water Resour. Res. 41, W05012. http://dx.doi.org/10.1029/ 2004WR003604.
Moriasi, D.N., Arnold, J.G., Van Liew, M.W., Binger, R.L., Harmel, R.D., Veith, T., 2007. Model evaluation guidelines for systematic quantification of accuracy in watershed simulations. Trans. ASABE 50 (3), 885-900.

Moussa, R., Chahinian, N., Bocquillon, C., 2007. Distributed hydrological modelling of a Mediterranean mountainous catchment-model construction and multi-site validation. J. Hydrol. 337 (1), 35-51.

Mroczkowski, M., Raper, G.P., Kuczera, G., 1997. The quest for more powerful validation of conceptual catchment models. Water Resour. Res. 33, 2325-2335.

Nash, J.E., Sutcliffe, J.V., 1970. River flow forecasting through conceptual models part I-A discussion of principles. J. Hydrol. 10 (3), 282-290.

Parajka, J., Merz, R., Blöschl, G., 2007. Uncertainty and multiple objective calibration in regional water balance modelling: case study in 320 Austrian catchments. Hydrol. Process. 21 (4), 435-446.

Paredes-Arquiola, J., Andreu-Álvarez, J., Martín-Monerris, M., Solera, A., 2010. Water quantity and quality models applied to the Jucar River Basin, Spain. Water Resour. Manage. 24 (11), 2759-2779.

Pisinaras, V., Petalas, C., Gikas, G.D., Gemitzi, A., Tsihrintzis, V.A., 2010. Hydrological and water quality modeling in a medium-sized basin using the Soil and Water Assessment Tool (SWAT). Desalination 250 (1), 274-286.

Refsgaard, J.C., Storm, B., 1995. MIKE SHE. In: Singh, V.P. (Ed.), Computer Models of Watershed Hydrology. Water Resource Publications, CO, USA, pp. 806-846.

Santhi, C., Arnold, J.G., Williams, J.R., Dugas, W.A., Srinivasan, R., Hauck, L.M., 2001 Validation of the SWAT model on a large river basin with point and nonpoint sources. J. Am. Water Resour. Assoc. 37 (5), 1169-1188.

Schoups, G., Hopmans, J.W., Young, C.A., Vrugt, J.A., Wallender, W.W., 2005. Multicriteria optimization of a regional spatially-distributed subsurface water flow model. J. Hydrol. 311 (1), 20-48.

Shafii, M., De Smedt, F., 2009. Multi-objective calibration of a distributed hydrological model (WetSpa) using a genetic algorithm. Hydrol. Earth Syst. Sci. 13 (11), 2137-2149.

Sharpley, A.N., Williams, J.R., 1990. EPIC-erosion/productivity impact calculator: 1. Model documentation. Technical Bulletin-United States Department of Agriculture.

Sincock, A.M., Wheater, H.S., Whitehead, P.G., 2003. Calibration and sensitivity analysis of a river water quality model under unsteady flow conditions. J. Hydrol. 277 (3), 214-229.

Srinivas, N., Deb, K., 1994. Multiobjective optimization using nondominated sorting in genetic algorithms. IEEE Trans. Evolut. Comput. 2 (3), 221-248.

Suen, J.P., Eheart, J.W., 2006. Reservoir management to balance ecosystem and human needs: incorporating the paradigm of the ecological flow regime. Water Resour. Res. 42 (3).

Tang, Y., Reed, P., Wagener, T., 2006. How effective and efficient are multiobjective evolutionary algorithms at hydrologic model calibration? Hydrol. Earth Syst. Sci. 10 (2), 289-307.

Tapia, M.G.C., Coello, C.A.C., 2007. Applications of multi-objective evolutionary algorithms in economics and finance: a survey. IEEE Congr. Evol. Comput. 7, 532-539.

Tesoriero, A.J., Duff, J.H., Wolock, D.M., Spahr, N.E., Almendinger, J.E., 2009. Identifying pathways and processes affecting nitrate and orthophosphate inputs to streams in agricultural watersheds. J. Environ. Qual. 38, 1892-1900.

van Griensven, A., Meixner, T., 2007. A global and efficient multi-objective autocalibration and uncertainty estimation method for water quality catchment models. J. Hydroinform. 9 (4), 277-291.

van Griensven, A., Bauwens, W., 2003. Multiobjective autocalibration for semidistributed water quality models. Water Resour. Res. 39 (12).

van Griensven, A., Meixner, T., Grunwald, S., Bishop, T., Diluzio, M., Srinivasan, R., 2006. A global sensitivity analysis tool for the parameters of multi-variable catchment models. J. Hydrol. 324 (1), 10-23.

Vrugt, J.A., Diks, C.G.H., Bouten, W., Gupta, H.V., Verstraten, J.M., 2005. Towards a complete treatment of uncertainty in hydrologic modelling: combining the strengths of global optimization and data assimilation. Water Resour. Res. 41 (1), W01017. http://dx.doi.org/10.1029/2004WR003059.

Vrugt, J.A., Gupta, H.V., Bastidas, L.A., Bouten, W., Sorooshian, S., 2003. Effective and efficient algorithm for multiobjective optimization of hydrologic models. Water Resour. Res. 39 (8).

Wang, J., Xiao, W., Wang, H., Chai, Z., Niu, C., Li, W., 2013. Integrated simulation and assessment of water quantity and quality for a river under changing environmental conditions. Chinese Sci. Bull. 58 (27), 3340-3347.

White, K.L., Chaubey, I., 2005. Sensitivity analysis, calibration, and validations for a multisite and multivariable SWAT model. J. Am. Water Resour. Assoc. 41 (5), 1077-1089.

Xia, J., Wang, G.S., Tan, G., Ye, A.Z., Huang, G.H., 2005. Development of distributed time-variant gain model for nonlinear hydrological systems. Sci. China Earth Sci. 48 (6), 713-723.

Yang, J., Reichert, P., Abbaspour, K.C., 2007. Bayesian uncertainty analysis in distributed hydrologic modeling: a case study in the Thur River basin (Switzerland). Water Resour. Res. 43, W10401.

Yang, J., Reichert, P., Abbaspour, K.C., Xia, J., Yang, H., 2008. Comparing uncertainty analysis techniques for a SWAT application to the Chaohe Basin in China. J. Hydrol. 358 (1-2), 1-23.

Yapo, P.O., Gupta, H.V., Sorooshian, S., 1998. Multi-objective global optimization for hydrologic models. J. Hydrol. 204 (1), 83-97.

Yen, H., Wang, X.Y., Fontane, D.G., Harmel, R.D., Arabi, M., 2014. A framework for propagation of uncertainty contributed by parameterization, input data, model structure, and calibration/validation data in watershed modeling. Environ. Model. Softw. 54, 211-221. 
Zhou, J., Ouyang, S., Wang, X., Ye, L., Wang, H., 2014. Multi-objective parameter calibration and multi-attribute decision-making: an application to conceptual hydrological model calibration. Water Resour. Manage. 28, 767-783.

Zitzler, E., Thiele, L., 1999. Multiobjective evolutionary algorithms: a comparative case study and the strength Pareto approach. IEEE Trans. Evolut. Comput. 3 (4), 257-271.

Zhang, H., Huang, G.H., Wang, D., Zhang, X., 2011. Multi-period calibration of a semi-distributed hydrological model based on hydroclimatic clustering. Adv. Water Resour. 34 (10), 1292-1303.
Zhang, Y., Xia, J., Shao, Q., Zhai, X., 2013. Water quantity and quality simulation by improved SWAT in highly regulated Huai River Basin of China. Stoch. Environ. Res. Risk A 27 (1), 11-27.

Zhang, Y.Y., Shao, Q.X., Ye, A.Z., Xing, H.T., Xia, J., 2016. Integrated water system simulation by considering hydrological and biogeochemical processes: mode development, with parameter sensitivity and autocalibration. Hydrol. Earth Syst. Sci. 20, 529-553. 